2012-08-15

\title{
A Review on the Visible Light Active Titanium Dioxide Photocatalysts for Environmental Applications
}

\author{
Miguel Pelaez \\ University of Cincinnati \\ Nicholas Nolan \\ Technological University Dublin \\ Suresh Pillai \\ Technological University Dublin, suresh.pillai@tudublin.ie
}

See next page for additional authors

Follow this and additional works at: https://arrow.tudublin.ie/ehsiart

Part of the Environmental Sciences Commons, Materials Chemistry Commons, and the Polymer Chemistry Commons

\section{Recommended Citation}

Pelaez, M. et al (2012). A Review on the Visible Light Active Titanium Dioxide Photocatalysts for Environmental Applications. Applied Catalysis B:Environmental, vol. 125, pp. 331-349. doi:10.1016/ j.apcatb.2012.05.036

This Article is brought to you for free and open access by the ESHI Publications at ARROW@TU Dublin. It has been accepted for inclusion in Articles by an authorized administrator of ARROW@TU Dublin. For more information, please contact arrow.admin@tudublin.ie, aisling.coyne@tudublin.ie,gerard.connolly@tudublin.ie. Funder: SFI, NSF, InvestNI

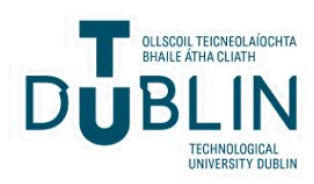




\section{Authors}

Miguel Pelaez, Nicholas Nolan, Suresh Pillai, Michael Seery, Polycarpos Falaras, Athanassios G. Kontos,

Patrick S.M. Dunlop, Jeremy W.J. Hamiltone, J. Anthony Byrne, Kevin O'Shea, Mohammad H. Entezari, and Dionysios D. Dionysiou 


\section{Accepted Manuscript}

Title: A review on the visible light active titanium dioxide photocatalysts for environmental applications

Authors: Miguel Pelaez, Nicholas T. Nolan, Suresh C. Pillai, Michael K. Seery, Polycarpos Falaras, Athanassios G. Kontos, Patrick S.M. Dunlop, Jeremy W.J. Hamilton, J.Anthony Byrne, Kevin O'shea, Mohammad H. Entezari, Dionysios D. Dionysiou

PII: S0926-3373(12)00239-1

DOI: doi:10.1016/j.apcatb.2012.05.036

Reference: APCATB 12094

To appear in: Applied Catalysis B: Environmental

Received date: $28-3-2012$

Revised date: $21-5-2012$

Accepted date: $25-5-2012$

Please cite this article as: M. Pelaez, N.T. Nolan, S.C. Pillai, M.K. Seery, P. Falaras, A.G. Kontos, P.S.M. Dunlop, J.W.J. Hamilton, J.A. Byrne, K. O'shea, M.H. Entezari, D.D. Dionysiou, A review on the visible light active titanium dioxide photocatalysts for environmental applications*, Applied Catalysis B, Environmental (2010), doi:10.1016/j.apcatb.2012.05.036

This is a PDF file of an unedited manuscript that has been accepted for publication. As a service to our customers we are providing this early version of the manuscript. The manuscript will undergo copyediting, typesetting, and review of the resulting proof before it is published in its final form. Please note that during the production process errors may be discovered which could affect the content, and all legal disclaimers that apply to the journal pertain. 
A review on the visible light active titanium dioxide photocatalysts for environmental applications*

MIGUEL PELAEZ, ${ }^{1}$ NICHOLAS T. NOLAN, ${ }^{2}$ SURESH C. PILLAI, ${ }^{2}$ MICHAEL K. SEERY, ${ }^{3}$ POLYCARPOS FALARAS, ${ }^{4}$ ATHANASSIOS G. KONTOS, ${ }^{4}$ PATRICK S.M. DUNLOP,${ }^{5}$ JEREMY W.J. HAMILTON, ${ }^{5}$ J.ANTHONY BYRNE, ${ }^{5}$ KEVIN O'SHEA, ${ }^{6}$ MOHAMMAD H. ENTEZARI ${ }^{7}$ and DIONYSIOS D. DIONYSIOU ${ }^{1, \S}$

$11{ }^{I}$ Environmental Engineering and Science Program, School of Energy, Environmental, Biological, and Medical Engineering, University of Cincinnati, Cincinnati, Ohio 45221-0071, USA

${ }^{2}$ Center for Research in Engineering Surface Technology (CREST)

DIT FOCAS Institute, Kevin St, Dublin 8, Ireland

$15{ }^{3}$ School of Chemical and Pharmaceutical Sciences, Dublin Institute of Technology, Kevin St., Dublin 8,

$18{ }^{5}$ Nanotechnology and Integrated BioEngineering Centre, School of Engineering, University of Ulster,

${ }^{6}$ Department of Chemistry and Biochemistry, Florida International University, University Park, Miami, Florida 3319, USA

$24 *$ All authors have contributed equally to this review.

26 §Corresponding author phone: (513) 556-0724; fax: (513) 556-2599; e-mail:

27 dionysios.d.dionysiou@uc.edu. 


\section{Abstract}

Fujishima and Honda (1972) demonstrated the potential of titanium dioxide $\left(\mathrm{TiO}_{2}\right)$ semiconductor materials to split water into hydrogen and oxygen in a photoelectrochemical cell. Their work triggered the development of semiconductor photocatalysis for a wide range of environmental and energy applications. One of the most significant scientific and commercial advances to date has been the development of visible light active (VLA) $\mathrm{TiO}_{2}$ photocatalytic materials. In this review, a background on $\mathrm{TiO}_{2}$ structure, properties and electronic properties in photocatalysis is presented. The development of different strategies to modify $\mathrm{TiO}_{2}$ for the utilization of visible light, including non metal and/or metal doping, dye sensitization and coupling semiconductors are discussed. Emphasis is given to the origin of visible light absorption and the reactive oxygen species generated, deduced by physicochemical and photoelectrochemical methods. Various applications of $\mathrm{VLA} \mathrm{TiO}_{2}$, in terms of environmental remediation and in particular water treatment, disinfection and air purification, are illustrated. Comprehensive studies on the photocatalytic degradation of contaminants of emerging concern, including endocrine disrupting compounds, pharmaceuticals, pesticides, cyanotoxins and volatile organic compounds, with $\mathrm{VLA}^{\mathrm{TiO}_{2}}$ are discussed and compared to conventional UV-activated $\mathrm{TiO}_{2}$ nanomaterials. Recent advances in bacterial disinfection using VLA $\mathrm{TiO}_{2}$ are also reviewed. Issues concerning test protocols for real visible light activity and photocatalytic efficiencies with different light sources have been highlighted.

Keywords: $\mathrm{TiO}_{2}$, visible, solar, water, treatment, air purification, disinfection, non-metal doping, anatase, rutile, $\mathrm{N}-\mathrm{TiO}_{2}$, metal doping, environmental application, reactive oxygen species, photocatalysis, photocatalytic, EDCs, cyanotoxins, emerging pollutants.

\section{Titanium dioxide- an Introduction}

\section{$1.1 \mathrm{TiO}_{2}$ structures and properties}

Titanium dioxide $\left(\mathrm{TiO}_{2}\right)$ exists as three different polymorphs; anatase, rutile and brookite [1]. The primary source and the most stable form of $\mathrm{TiO}_{2}$ is rutile. All three polymorphs can be readily synthesised in the laboratory and typically the metastable anatase and brookite will transform to the thermodynamically stable rutile upon calcination at temperatures exceeding $\sim 600{ }^{\circ} \mathrm{C}$ [2]. In all three forms, titanium $\left(\mathrm{Ti}^{4+}\right)$ atoms are coordinated to six oxygen $\left(\mathrm{O}^{2-}\right)$ atoms, forming $\mathrm{TiO}_{6}$ octahedra [3]. Anatase is made up of corner (vertice) sharing octahedra which form (001) planes (Figure 1a) resulting in a tetragonal structure. In rutile the octahedra share edges at (001) planes to give a tetragonal structure (Figure 1b), and in brookite both edges and corners are shared to give an orthorhombic structure (Figure 1c) [2,4-7].

Titanium dioxide is typically an $n$-type semiconductor due to oxygen deficiency [8]. The band gap is $3.2 \mathrm{eV}$ for anatase, $3.0 \mathrm{eV}$ for rutile, and $\sim 3.2 \mathrm{eV}$ for brookite [9-11]. Anatase 
and rutile are the main polymorphs and their key properties are summarized in Table 1 [12-14]. $\mathrm{TiO}_{2}$ is the most widely investigated photocatalyst due to high photo-activity, low cost, low toxicity and good chemical and thermal stability $[12,15,16]$. In the past few decades there have been several exciting breakthroughs with respect to titanium dioxide. The first major advance was in 1972 when Fujishima and Honda reported the photoelectrochemical splitting of water using a $\mathrm{TiO}_{2}$ anode and a $\mathrm{Pt}$ counter electrode [17]. Titanium dioxide photocatalysis was first used for the remediation of environmental pollutants in 1977 when Frank and Bard reported the reduction of $\mathrm{CN}^{-}$in water $[18,19]$. This led to a dramatic increase in the research in this area because of the potential for water and air purification through utilization of "free" solar energy [12,14,20]. Other significant breakthroughs included Wang et al. (1977), who reported $\mathrm{TiO}_{2}$ surfaces with excellent anti-fogging and self-cleaning abilities, attributed to the super hydrophilic properties of the photoexcited $\mathrm{TiO}_{2}$ surfaces [21] and use of nano titanium dioxide in an efficient dye sensitized solar cell (DSSC), reported by Graetzel and O'Regan in 1991 [22].

\subsection{Electronic processes in $\mathrm{TiO}_{2}$ photocatalysis}

Photocatalysis is widely used to describe the process in which the acceleration of a reaction occurs when a material, usually a semiconductor, interacts with light of sufficient energy (or of a certain wavelength) to produce reactive oxidizing species (ROS) which can lead to the photocatalytic transformation of a pollutant. It must be noted that during the photocatalytic reaction, at least two events must occur simultaneously in order for the successful production of reactive oxidizing species to occur. Typically, the first involves the oxidation of dissociatively adsorbed $\mathrm{H}_{2} \mathrm{O}$ by photogenerated holes, the second involves reduction of an electron acceptor by photoexcited electrons; these reactions lead to the production of a hydroxyl and superoxide radical anion, respectively [23].

It is clear that photocatalysis implies photon-assisted generation of catalytically active species rather that the action of light as a catalyst in a reaction [24,25]. If the initial photoexcitation process occurs in an adsorbate molecule, which then interacts with the ground state of the catalyst substrate, the process is referred to as a "catalyzed photoreaction", if, on the other hand, the initial photoexcitation takes place in the catalyst substrate and the photoexcited catalyst then interacts with the ground state adsorbate molecule, the process is a "sensitized photoreaction". In most cases, heterogeneous photocatalysis refers to semiconductor photocatalysis or semiconductor-sensitized photoreactions [23].

In photocatalysis, light of energy greater than the band gap of the semiconductor, excites an electron from the valence band to the conduction band (see Figure 2). In the case of anatase $\mathrm{TiO}_{2}$, the band gap is $3.2 \mathrm{eV}$, therefore UV light $(\lambda \leq 387 \mathrm{~nm})$ is required. The absorption of a photon excites an electron to the conduction band $\left(\mathrm{e}_{\mathrm{CB}}^{-}\right)$generating a positive hole in the valence band $\left(\mathrm{h}^{+}{ }_{\mathrm{VB}}\right)($ Eq. 1.1).

$$
\mathrm{TiO}_{2}+\mathrm{h} v \rightarrow \mathrm{h}^{+}{ }_{\mathrm{VB}}+\mathrm{e}_{\mathrm{CB}}^{-}
$$


Charge carriers can be trapped as $\mathrm{Ti}^{3+}$ and $\mathrm{O}^{-}$defect sites in the $\mathrm{TiO}_{2}$ lattice, or they can recombine, dissipating energy [26]. Alternatively, the charge carriers can migrate to the catalyst surface and initiate redox reactions with adsorbates [27]. Positive holes can oxidize $\mathrm{OH}^{-}$or water at the surface to produce ${ }^{\circ} \mathrm{OH}$ radicals (Eq. 1.2) which, are extremely powerful oxidants (Table 2). The hydroxyl radicals can subsequently oxidize organic species with mineralization producing mineral salts, $\mathrm{CO}_{2}$ and $\mathrm{H}_{2} \mathrm{O}$ (Eq. 1.5) [28].

$$
\begin{aligned}
& \mathrm{e}_{\mathrm{CB}}^{-}+\mathrm{h}^{+}{ }_{\mathrm{VB}} \rightarrow \text { energy } \\
& \mathrm{H}_{2} \mathrm{O}+\mathrm{h}^{+}{ }_{\mathrm{VB}} \rightarrow{ }^{\circ} \mathrm{OH}+\mathrm{H}^{+} \\
& \mathrm{O}_{2}+\mathrm{e}_{\mathrm{CB}}^{-} \rightarrow \mathrm{O}_{2}{ }^{-} \\
& { }^{\circ} \mathrm{OH}+\text { pollutant } \rightarrow \rightarrow \rightarrow \mathrm{H}_{2} \mathrm{O}+\mathrm{CO}_{2} \\
& \mathrm{O}_{2}{ }^{-}+\mathrm{H}^{+} \rightarrow{ }^{\circ} \mathrm{OOH} \\
& { }^{\circ} \mathrm{OOH}+{ }^{\circ} \mathrm{OOH} \rightarrow \mathrm{H}_{2} \mathrm{O}_{2}+\mathrm{O}_{2} \\
& \mathrm{O}_{2}{ }^{-}+\text {pollutant } \rightarrow \rightarrow \rightarrow \mathrm{CO}_{2}+\mathrm{H}_{2} \mathrm{O} \\
& \cdot \mathrm{OOH}+\text { pollutant } \rightarrow \mathrm{CO}_{2}+\mathrm{H}_{2} \mathrm{O}
\end{aligned}
$$

Electrons in the conduction band can be rapidly trapped by molecular oxygen adsorbed on the titania particle, which is reduced to form superoxide radical anion $\left(\mathrm{O}_{2}{ }^{\circ}\right)(\mathrm{Eq}, 1.4)$ that may further react with $\mathrm{H}^{+}$to generate hydroperoxyl radical ('OOH) (Eq. 1.6) and further electrochemical reduction yields $\mathrm{H}_{2} \mathrm{O}_{2}$ (Eq. 1.7) [29,30]. These reactive oxygen species may also contribute to the oxidative pathways such as the degradation of a pollutant (Eq. 1.8 and 1.9) [26,28,29].

\subsection{Recombination}

Recombination of photogenerated charge carriers is the major limitation in semiconductor photocatalysis as it reduces the overall quantum efficiency [30]. When recombination occurs, the excited electron reverts to the valence band without reacting with adsorbed species (Eq. 1.2) [31] non-radiatively or radiatively, dissipating the energy as light or heat $[6,32]$.

Recombination may occur either on the surface or in the bulk and is in general facilitated by impurities, defects, or all factors which introduce bulk or surface imperfections into the crystal $[30,33]$. Serpone et al., found that trapping excited electrons as $\mathrm{Ti}^{3+}$ species occurred on a time scale of $\sim 30 \mathrm{ps}$ and that about $90 \%$ or more of the photogenerated electrons recombine within $10 \mathrm{~ns}$ [34]. Doping with ions [35-37], heterojunction coupling [38-40] and nanosized crystals [41,42] have all been reported to promote separation of the electron-hole pair, reducing recombination and therefore improve the photocatalytic activity. For example, the $\mathrm{TiO}_{2}$ crystallites of Evonik (Degussa) P25 contain a combination of anatase $(\sim 80 \%)$ and rutile $(\sim 20 \%)$. The conduction band potential of rutile is more positive than that of anatase which means that the rutile phase may act as an electron sink for photogenerated electrons from the conduction band of the anatase phase. Many researchers attribute the high photocatalytic activity of this preparation to the intimate contact between two phases, enhancing separation of photogenerated electrons and holes, and resulting in reduced recombination [43].

1.4 Strategies for improving $\mathrm{TiO}_{2}$ photoactivity 
Various strategies have been adopted for improving the photocatalytic efficiency of $\mathrm{TiO}_{2}$. They can be summarized as either morphological modifications, such as increasing surface area and porosity, or as chemical modifications, by incorporation of additional components in the $\mathrm{TiO}_{2}$ structure. Although visible light active (VLA) $\mathrm{TiO}_{2}$ photocatalysts require chemical modifications, which will be reviewed in the next section, their overall efficiencies have been significantly enhanced by controlling the semiconductor morphology.

The most commonly used $\mathrm{TiO}_{2}$ morphology is that of monodispersed nanoparticles wherein the diameter is controlled to give benefits from the small crystallite size (high surface area, reduced bulk recombination) without the detrimental effects associated with very small particles (surface recombination, low crystallinity) [44]. One dimensional (1D) titania nanostructures (nanotubes, nanorods, nanowires, nanobelts, nanoneedles) have been also formed by hydrothermal synthesis but high emphasis was given in titania self-assembled nanotubular films grown by electrochemical anodization on titanium metal foils. Advantages of such structures is their tailored morphology, controlled porosity, vectorial charge transfer $[45,46]$ and low recombination at grain boundaries that result in enhanced performance in photoinduced applications, mainly in photocatalysis $[45,47,48]$. An interesting use of $\mathrm{TiO}_{2}$ nanotubes in photocatalytic applications is the growth of freestanding flow-through membranes [45].

\section{Development of Visible Light Active (VLA) Titania Photocatalysts}

\subsection{Non metal doping}

\subsubsection{Nitrogen doping}

Ultraviolet light makes up only 4-5\% of the solar spectrum, whereas approximately $40 \%$ of solar photons are in the visible region. A major drawback of pure $\mathrm{TiO}_{2}$ is the large band gap meaning it can only be activated upon irradiation with photons of light in the UV domain ( $\lambda \leq 387 \mathrm{~nm}$ for anatase), limiting the practical efficiency for solar applications [49-51]. Therefore, in order to enhance the solar efficiency of $\mathrm{TiO}_{2}$ under solar irradiation, it is necessary to modify the nanomaterial to facilitate visible light absorption. Non-metal doping of $\mathrm{TiO}_{2}$ has shown great promise in achieving visible light active (VLA) photocatalysis, with nitrogen being the most promising dopant [52,53].

Nitrogen can be easily introduced in the $\mathrm{TiO}_{2}$ structure, due to its comparable atomic size with oxygen, small ionization energy and high stability. It was in 1986 when Sato discovered that addition of $\mathrm{NH}_{4} \mathrm{OH}$ in a titania sol, followed by calcination of the precipitated powder, resulted in a material that exhibited a visible light response $[54,55]$. Later on, Asahi and co-workers explored for first time the visible light activity of $\mathrm{N}$ doped $\mathrm{TiO}_{2}$ produced by sputter deposition of $\mathrm{TiO}_{2}$ under an $\mathrm{N}_{2} / \mathrm{Ar}$ atmosphere, followed by annealing under $\mathrm{N}_{2}$ [56]. Since then, there have been many reports dealing with 45 nitrogen doping of $\mathrm{TiO}_{2}$. Significant efforts are being devoted to investigating the 46 structural, electronic and optical properties of $\mathrm{N}$-doped $\mathrm{TiO}_{2}$, understanding the 
underlying mechanisms and improving the photocatalytic and self-cleaning efficiency under visible and solar light [57-59]. Comprehensive reviews have been published which summarize representative results of these studies [60,61]. Model pollutants that have been reported to be effectively degraded by VLA photocatalyst include phenols, methylene blue, methyl orange (although dyes have strong absorption in the visible range) and rhodamine $\mathrm{B}$, as well as several gaseous pollutants (e.g., volatile organic compounds, nitrogen oxides).

For the efficient incorporation of nitrogen into $\mathrm{TiO}_{2}$ either in the bulk or as a surface dopant, both dry and wet preparation methods have been adopted. Physical techniques such as sputtering [62-66] and ion implantation [67,68], rely on the direct treatment of $\mathrm{TiO}_{2}$ with energetic nitrogen ions. Gas phase reaction methods [69-71], atomic layer deposition [72] and pulsed laser deposition [73] have been successfully applied to prepare $\mathrm{N}-\mathrm{TiO}_{2}$, as well. However, the most versatile technique for the synthesis of $\mathrm{N}-\mathrm{TiO}_{2}$ nanoparticles is the sol-gel method, which requires relatively simple equipment and permits fine control of the material's nanostructure, morphology and porosity. Simultaneous $\mathrm{TiO}_{2}$ growth and $\mathrm{N}$ doping is achieved by hydrolysis of titanium alkoxide precursors in the presence of nitrogen sources. Typical titanium salts (titanium tetrachloride) and alkoxide precursors (including titanium tetra-isopropoxide, tetrabutyl orthotitanate) have been used. Nitrogen containing precursors used include aliphatic amines, nitrates, ammonium salts, ammonia and urea [74-76]. The synthesis root involves several steps; however, the main characteristic is that precursor hydrolysis is usually performed at room temperature. The precipitate is then dried to remove solvents, pulverized and calcined at temperatures from 200 to $600^{\circ} \mathrm{C}$.

One promising way to increase the nitrogen content in the $\mathrm{TiO}_{2}$ lattice is to combine the titanium precursors with a nitrogen-containing ligand, such as $\mathrm{Ti}^{4+}$-bipyridine or $\mathrm{Ti}^{4+}$ amine complexes $[77,78]$. An alternative soft chemical route is based on the addition of urea during the condensation of an alkoxide acidified solution, leading to interstitial surface doping and shift of the absorption edge well into the visible spectral range (from 3.2 to $2.3 \mathrm{eV}$ ) [79]. An innovative sol-gel related technique for the preparation of efficient visible-light active nanostructured $\mathrm{TiO}_{2}$ is the templating sol-gel method, utilizing titanium precursors combined with nitrogen-containing surfactants. Specifically, successful synthesis of visible light activated $\mathrm{N}-\mathrm{TiO}_{2}$ has been achieved by a simple solgel method employing dodecylammonium chloride (DDAC) as surfactant [80]. The DDAC surfactant acts simultaneously as a pore templating material to tailor-design the structural properties of $\mathrm{TiO}_{2}$ (see Figure 3) as well as a nitrogen dopant to induce visiblelight photoactivity and unique reactivity and functionality for environmental applications $[81,82]$.

In a different approach $\mathrm{N}-\mathrm{TiO}_{2}$, was synthesized via two successive steps: synthesis of $\mathrm{TiO}_{2}$ and then nitrogen doping using various nitrogen-containing chemicals (e.g. urea, 43 ethylamine, $\mathrm{NH}_{3}$ or gaseous nitrogen) at high temperatures [53,83-85] or inductively 44 coupled plasma containing a wide range of nitrogen precursors [86]. In that case, the 45 nitrogen atoms predominantly resided on the $\mathrm{TiO}_{2}$ surface. The origin of the visible-light 
photocatalytic activity in these methods may arise from condensed aromatic s-triazine compounds containing melem and melon units [74].

3

4

Although most reports on $\mathrm{N}-\mathrm{TiO}_{2}$ concern the anatase polymorphic phase, visible light active $\mathrm{N}-\mathrm{TiO}_{2}$ with anatase-rutile mixed phase (Figure 4) has also been prepared by tuning the parameters of the sol-gel synthesis. Such heterojunction photocatalysts seem to effectively transfer photo-excited electrons from the conduction band of anatase to that of rutile, favoring electron-hole separation and enhancing the visible light photocatalytic activity. [87,88]. Etacheri et al., have successfully developed nitrogen doped anataserutile heterojunctions which were found to be nine times more photocatalytically active at wavelengths higher than $450 \mathrm{~nm}$ (blue filter) in comparison with Evonik P25.

Most of the above methods have also been successfully applied for the doping of 1D titania nanostructures with nitrogen. In this way, $\mathrm{N}$-doped anatase titania nanobelts were prepared via hydrothermal processing and subsequent heat treatment in $\mathrm{NH}_{3}$ [89]. Similar post-treatment was employed for doping anodized titania nanotubes [90], while high energy ion implantation was found to be more efficient in introducing $\mathrm{N}$ atoms in the $\mathrm{TiO}_{2}$ lattice [91]. Nitrogen localized states have also been introduced into highly ordered $\mathrm{TiO}_{2}$ nanotubes via nitrogen plasma [92]. Visible light-active $\mathrm{N}-\mathrm{TiO}_{2}$ nanoarray films have also been prepared on sacrificial anodized alumina liquid phase deposition with urea mixed with $\left(\mathrm{NH}_{4}\right)_{2} \mathrm{TiF}_{6}$ aqueous solution [93]. Recently, surface $\mathrm{N}$-doping on titania nanowires, their lateral dimensions reaching the atomic scale, was achieved by the introduction of amines during the condensation stage of the titania precursor [94]. Other approaches for preparing doped $\mathrm{TiO}_{2}$ nanotubes include employment of nitrogen sources in the electrolyte solutions of electrochemical anodization [95] or in the initial solution of hydrothermal growth [96,97].

Many results, up to now, describe nitrogen doping as substitutional element on the oxygen lattice sites or at interstitial lattice sites. The two sites can be in principle discriminated by X-ray photoelectron spectroscopy (XPS) relying on the distinct N1s binding energies at 396 and $400 \mathrm{eV}$, respectively [52,70,98-100], although there is still some debate concerning the attribution of the $400 \mathrm{eV}$ peak to interstitial or molecularly chemisorbed nitrogen $[65,66]$. Compared with the UV activity of undoped $\mathrm{TiO}_{2}$, the visible light activity of $\mathrm{N}-\mathrm{TiO}_{2}$ is rather low. There is also some conflict in the literature concerning the preferred $\mathrm{N}$ sites, substitutional or interstitial, which induce the highest photocatalytic action [70,84,100,101]. Independently of the origin of visible light absorption in substitutional or interstitial nitrogen discrete energy states, the low photocatalytic efficiency is mainly attributed to the limited photo-excitation of electrons in such narrow states, the very low mobility of the corresponding photo-generated holes [102] and the concomitant increase of the recombination rate due to the creation of oxygen vacancies by doping [103].

\subsubsection{Other non-metal doping (F, C, S)}

Fluorine doping does not shift the $\mathrm{TiO}_{2}$ band gap; however it improves the surface acidity and causes formation of reduced $\mathrm{Ti}^{3+}$ ions due to the charge compensation between $\mathrm{F}^{-}$and 
$\mathrm{Ti}^{4+}$. Thus, charge separation is promoted and the efficiency of photoinduced processes is improved [104]. Insertion of fluorine into the $\mathrm{TiO}_{2}$ crystal lattice has also been reported to elevate the anatase to rutile phase transformation temperature. Padmanabhan et al., successfully modified titanium isopropoxide with trifluoroacetic acid carrying out a solgel synthesis. The resulting material proved to be more photocatalytically active than Evonik P25 while also retaining anatase at temperatures of up to $900{ }^{\circ} \mathrm{C}$ [105].

Carbon, phosphorous and sulphur as dopants have also shown positive results for visible light activity in $\mathrm{TiO}_{2}[49,50]$. The non-metal dopants effectively narrow the band gap of states within the conduction and valence bands from electronic perturbations, gives rise to band gap narrowing [108]. Not only does this allow for visible light absorption but the presence of trap sites within the $\mathrm{TiO}_{2}$ bands increases the lifetime of photo-generated charge carriers.

Successful insertion of sulfur into the $\mathrm{TiO}_{2}$ lattice is far more difficult to achieve than nitrogen, due to its larger ionic radius. Insertion of cationic sulfur $\left(S^{6+}\right)$ is chemically favourable over the ionic form $\left(\mathrm{S}^{2-}\right)$ lattice. Cationic (sulfur) and anionic (nitrogen) codoped with $\mathrm{TiO}_{2}$ has also been synthesised from a single source, ammonium sulfate, using a simple sol-gel technique [109]. Periyat et al., successfully developed S-doped $\mathrm{TiO}_{2}$ through modification of titanium isopropoxide with sulphuric acid. They found that formation of titanyl oxysulfate results in the retention of anatase at increased temperatures $\left(\geq 800^{\circ} \mathrm{C}\right)$ and that the presence of sulfur causes increased visible light photocatalytic activity of the synthesised materials. [110]. Recently, visible lightactivated sulfur doped $\mathrm{TiO}_{2}$ films were successfully synthesized using a novel sol-gel method based on the self-assembly technique with a nonionic surfactant to control nanostructure and $\mathrm{H}_{2} \mathrm{SO}_{4}$ as an inorganic sulfur source [111]. Sulfur species distributed uniformly throughout the films were identified both as $\mathrm{S}^{2-}$ ions related to anionic substitutional doping of $\mathrm{TiO}_{2}$ as well as $\mathrm{S}^{6+} / \mathrm{S}^{4+}$ cations, attributed mainly to the presence of surface sulfate groups. A strong electron paramagnetic resonance (EPR) signal, whose intensity correlated with the sulfur content and most importantly was markedly enhanced under visible light irradiation, implied formation of localized energy states in the $\mathrm{TiO}_{2}$ band gap due to anion doping and/or oxygen vacancies. Calcination at $350^{\circ} \mathrm{C}$ for $2 \mathrm{~h}$ provided sulfur doped $\mathrm{TiO}_{2}$ films with the highest sulfur content and BET surface area, small crystallite size, high porosity, and large pore volume together with very smooth and uniform surface. The corresponding mesoporous $\mathrm{S}_{-} \mathrm{TiO}_{2}$ film was the most effective photocatalyst for the degradation of microcystin-LR (MC-LR) under visible light irradiation.

\subsubsection{Non-metal co-doping}

$\mathrm{N}-\mathrm{F}$ co-doped $\mathrm{TiO}_{2}$ has been explored in visible light photocatalysis $[112,113]$ due to the similar structural preferences of the two dopants. In addition, the combined structure retains the advantages of $\mathrm{N}$-doping in high visible light response and the F-doping significant role in charge separation. Furthermore, synergetic effects of the co-doping have been found. In fact, surface fluorination inhibits phase transformation from anatase 
to rutile and removal of N-dopants during annealing [114]. In addition, it reduces the energy cost of doping and also the amount of oxygen defects in the lattice, as a consequence of the charge compensation between the nitrogen (p-dopant) and the fluorine (n-dopant) impurities [115]. These effects stabilize the composite system and effectively reduce the concomitant electron-hole recombination that hampers the photocatalytic performance of singly doped $\mathrm{N}-\mathrm{TiO}_{2}$.

The synergistic approach of the N-F doping has been further exploited employing a modified sol-gel technique based on a nitrogen precursor and a Zonyl FS-300 nonionic fluorosurfactant as both fluorine source and pore template material to tailor-design the structural properties of $\mathrm{TiO}_{2}$ [116]. The obtained materials are active under visible light illumination and have been used for the photocatalytic degradation of a variety of pollutants in water. Very recently, these N-F doped titania materials were successfully immobilized on glass substrates employing the dip-coating method with subsequent drying under infrared lamp, followed by calcination at $400^{\circ} \mathrm{C}$. The nanostructured titania doped thin films preserve their visible light induced catalytic activity [117]. Furthermore, comparative EPR measurements between the co-doped and reference samples identified distinct $\mathrm{N}$ spin species in $\mathrm{NF}^{-\mathrm{TiO}_{2}}$, with a high sensitivity to visible light irradiation. The abundance of these paramagnetic centers verifies the formation of localized intra-gap states in $\mathrm{TiO}_{2}$ and implies synergistic effects between fluorine and nitrogen dopants [117].

Significant improvement of the visible-light photoactivity of N-F co-doped titania films has been observed by employing an inverse opal growth method, using a silica colloidal crystal as a template for liquid phase deposition of $\mathrm{NF}^{-\mathrm{TiO}_{2}}$. In this way, hierarchical meso-macroporous structures are prepared which promote efficient and stable photocatalysis via tuned morphology and photon multiple scattering effects [118].

\subsubsection{Oxygen rich $\mathrm{TiO}_{2}$ modification}

Following another approach, recently the visible light active photocatalytic properties have been achieved by the in-situ generation of oxygen through the thermal decomposition of peroxo-titania complex [119]. Increased Ti-O-Ti bond strength and upward shifting of the valence band (VB) maximum were responsible for the visible light activity. The upward shifting of the VB maximum for oxygen rich titania is identified as another crucial reason responsible for efficient visible light absorption. Typical band gap structures of control and oxygen rich titania samples obtained are represented in Figure 5.

\subsection{Metal Deposition}

\subsubsection{Noble metal and transition metal deposition.}

Modifications of $\mathrm{TiO}_{2}$ with transition metals such as $\mathrm{Cr}, \mathrm{Co}, \mathrm{V}$ and $\mathrm{Fe}$ have extended the spectral response of $\mathrm{TiO}_{2}$ well into the visible region also improving photocatalytic activity [108,120-123]. However, transition metals may also act as recombination sites 
metals have also been found to cause thermal instability to the anatase phase of $\mathrm{TiO}_{2}$ [30]. Kang argues that despite the fact that a decrease in band gap energy has been achieved by many groups through metal doping, photocatalytic activity has not been remarkably enhanced because the metals introduced were not incorporated into the $\mathrm{TiO}_{2}$ framework. In addition, metals remaining on the $\mathrm{TiO}_{2}$ surface block reaction sites [124]. While Morikawa et al., showed that doping $\mathrm{TiO}_{2}$ with $\mathrm{Cr}$ was found to reduce photocatalytic activity but $\mathrm{Cr}$ and $\mathrm{V}$ ion implanted $\mathrm{TiO}_{2}$ showed higher photocatalytic performances than bare $\mathrm{TiO}_{2}$ did for the decomposition of $\mathrm{NO}$ under solar irradiation [125]. Another technique involves modifying $\mathrm{TiO}_{2}$ with transition metals such as $\mathrm{Fe}, \mathrm{Cu}$, $\mathrm{Co}, \mathrm{Ni}, \mathrm{Cr}, \mathrm{V}, \mathrm{Mn}, \mathrm{Mo}, \mathrm{Nb}, \mathrm{W}, \mathrm{Ru}, \mathrm{Pt}$ and $\mathrm{Au}$ [126-135]. The incorporation of transition metals in the titania crystal lattice may result in the formation of new energy levels between VB and $\mathrm{CB}$, inducing a shift of light absorption towards the visible light region. Photocatalytic activity usually depends on the nature and the amount of doping agent. Possible limitations are photocorrosion and promoted charge recombination at metal sites [127].

Deposition of noble metals like $\mathrm{Ag}, \mathrm{Au}, \mathrm{Pt}$ and $\mathrm{Pd}$ on the surface of $\mathrm{TiO}_{2}$ enhances the photocatalytic efficiency under visible light by acting as an electron trap, promoting interfacial charge transfer and therefore delaying recombination of the electron-hole pair [126,136-140]. Hwang et al., showed that platinum deposits on $\mathrm{TiO}_{2}$ trap photogenerated electrons, and subsequently increase the photo-induced electron transfer rate at the interface. Seery et al., showed enhanced visible light photocatalysis with Ag modified $\mathrm{TiO}_{2}$ [141]. While Gunawan et al., demonstrated the reversible photoswitching of nano silver on $\mathrm{TiO}_{2}$ where reduced silver on $\mathrm{TiO}_{2}$ support exposed to visible light (> $450 \mathrm{~nm}$ ) resulted in excitation and reverse electron flow from silver to the $\mathrm{TiO}_{2}$ support, oxidising silver $\left(\mathrm{Ag}^{0} \rightarrow \mathrm{Ag}^{+}\right)$in the process [142]. The visible light responsiveness of $\mathrm{TiO}_{2}$ was accredited to the surface plasmon resonance of silver nanoparticles (Figure 6) [142,143].

\subsection{Dye sensitization in photocatalysis}

Dye photosensitization has been reported by different groups and to be one of the most effective ways to extend the photoresponse of $\mathrm{TiO}_{2}$ into the visible region [144-147]. Indeed these types of reactions are exploited in the well known dye sensitized solar cells [22]. The mechanism of the dye sensitized photo-degradation of pollutants is based on the absorption of visible light for exciting an electron from the highest occupied molecular orbital (HOMO) to the lowest unoccupied molecular orbital (LUMO) of a dye. The excited dye molecule subsequently transfers electrons into the conduction band of $\mathrm{TiO}_{2}$, while the dye itself is converted to its cationic radical. The $\mathrm{TiO}_{2}$ acts only as a mediator for transferring electrons from the sensitizer to the substrate on the $\mathrm{TiO}_{2}$ surface as electron acceptors, and the valence band of $\mathrm{TiO}_{2}$ remains unaffected. In this process, the LUMO of the dye molecules should be more negative than the conduction band of $\mathrm{TiO}_{2}$. The injected electrons hop over quickly to the surface of titania where they are scavenged by molecular oxygen to form superoxide radical $\mathrm{O}_{2}{ }^{--}$and hydrogen peroxide radical ${ }^{\circ} \mathrm{OOH}$. These reactive species can also disproportionate to give hydroxyl radical [148150]. In addition to the mentioned species, singlet oxygen may also be formed under certain experimental conditions. Oxygen has two singlet excited states above the triplet 
ground ones. Such relatively long live oxygen species may be produced by quenching of the excited state of the photosensitizer by oxygen. The subsequent radical chain reactions can lead to the degradation of the dye [150].

Knowledge of interfacial electron transfer between semiconductor and molecular adsorbates is of fundamental interest and essential for applications of these materials [151-154]. Ultrafast electron injection has been reported for many dye-sensitized $\mathrm{TiO}_{2}$ systems. This injection depends on the nature of the sensitizer, the semiconductor, and their interaction. Asbury et al., observed very different electron injection times from femto to pico second by changing the semiconductor under the same conditions [152].

\subsection{Coupled semiconductors}

Many efforts have been made in the synthesis of different coupled semiconductors such as $\mathrm{ZnO} / \mathrm{TiO}_{2}$ [155], $\mathrm{CdS} / \mathrm{TiO}_{2}$ [156], and $\mathrm{Bi}_{2} \mathrm{~S}_{3} / \mathrm{TiO}_{2}$ [157]. The synthesized couples significantly enhance the photocatalytic efficiency by decreasing the recombination rate of the photogenerated electron-hole pairs and present potential applications in water splitting, organic decomposition, and photovoltaic devices [158-160]. These composites were also considered as promising materials to develop a high efficiency photocatalyst activated with visible light. They can also compensate the disadvantages of the individual components, and induce a synergistic effect such as an efficient charge separation and improvement of photostability [160,161]. Therefore, visible light-driven coupled photocatalysts that can decompose organic material are of great interest $[159,162,163]$.

Analysis of the microstructure and phase composition of the coupled semiconductor of $\mathrm{BiFeO}_{3} / \mathrm{TiO}_{2}$ revealed that a core-shell structure was formed [164]. This couple resulted in extended photo-absorption bands into the visible which was dependent on the $\mathrm{BiFeO}_{3}$ content. This couple was reported to be more effective for the photocatalytic degradation of congo red dye under visible light irradiation, as compared to pure $\mathrm{BiFeO}_{3}$ and $\mathrm{TiO}_{2}$ powders. Sensitizing $\mathrm{TiO}_{2}$ nanotube arrays with $\mathrm{ZnFe}_{2} \mathrm{O}_{4}$ was found to enhance photoinduced charge separation and to extend the photoresponse from the UV to the visible region, too [165].

Up until now, the main efforts have been devoted to the synthesis of various core-shell nanocrystals. The prevalent view point is that it requires a lattice matching between shells and core materials to achieve a better passivation and minimize structural defects [166169]. In addition, the coupling of a large band gap semiconductor with a smaller one, which can be activated with visible light, is of great interest for the degradation of organic pollutants using solar radiation. Blocking trap states by coating the particles with thin layers of a wide band gap material can lead to a drastic enhancement of the photostability [170-172]. For instance, $\mathrm{CdS}$ is a fascinating material with ideal band gap energy for solar and visible light applications $(2.4 \mathrm{eV})$. However, $\mathrm{CdS}$ is prone to photoanodic corrosion in aqueous environments. To overcome this stability problem and improve the photoactivity, $\mathrm{CdS}$ has been combined with a wide band gap semiconductor, such as $\mathrm{ZnO}$ and $\mathrm{TiO}_{2}[159,173]$, and this coupling gives improved charge separation of

46 photogenerated electrons and holes (see Figure 7). 
In addition to the flat band potential of the components, the photocatalytic performance of the coupled semiconductors is also related to the geometry of the particles, the contact surface between particles, and the particle size [174-175]. These parameters strongly depend on the manner with which the couples are prepared. Various core/shell type nanocrystals have been extensively studied using different methods. Synthesis methods normally require high temperatures, long times, strict inert atmosphere protection and complex multistep reaction process.

By applying ultrasound under specific conditions, there is the possibility of synthesizing nano-composites in a short time, under mild conditions, in air, and without calcination [156]. For example, $\mathrm{TiO}_{2}$-coated nanoparticles with a core-shell structure have been prepared with ultrasound treatment. The $\mathrm{TiO}_{2}$ was found to be uniformly coated on the surface of $\mathrm{CdS}$ and this led to an enlargement of the nanoparticles. In the absence of ultrasound, the formation of large irregular aggregates was observed. The UV-Vis absorbance spectra of the pure and composite semiconductors are shown in Figure 8 [156]. The absorption band of CdS nanoparticles was found at around 450-470 nm in comparison with the bulk crystalline $\mathrm{CdS}$ which appeared at about $515 \mathrm{~nm}(E g=2.4 \mathrm{eV})$ [176]. In the case of $\mathrm{TiO}_{2}$, the onset absorption for nanoparticles prepared under ultrasound was about $360 \mathrm{~nm}$, while for the bulk it was about $385 \mathrm{~nm}(E g=3.2 \mathrm{eV})$ [177]. It is found that modification of $\mathrm{TiO}_{2}$ with $\mathrm{CdS}$ particles extends the optical absorption spectrum into the visible region in comparison with that of pure $\mathrm{TiO}_{2}$. Increasing the amount of $\mathrm{TiO}_{2}$ led to a further red-shift of the absorption band in composite photocatalysts. The red shift of spectra are typical characteristics of core-shell nano-crystals, originating from the efficient diminishing of the surface defects of core nano-crystals after capping them with higher band gap shells [169]. This is in agreement with the previous report by Kisch et al. that the band gap of CdS employed in composite photocatalysts is shifted by an electronic semiconductor-support interaction $[178,179]$.

The synthesized $\mathrm{CdS} / \mathrm{TiO}_{2}$ nano-composite system was applied for the removal of Reactive Black 5 in aqueous solution, under different conditions, and employing visible and solar light irradiation. The mechanism for the degradation that is proposed is based on the reactions in Figure 9 [156]. In semiconductor core-shell structures electronic interactions that occur at the heterojunction can trap photo-generated electrons at the interface and improve the efficiency of the photocatalytic activity. The photo-generated electrons and holes induce redox reactions according to the relative potentials of the conduction and valence bands of the two semiconductors. Such core-shell nanocomposites may bring new insights into the design of highly efficient photocatalysts and potential applications in technology.

\subsection{Defect induced VLA photocatalysis}

VLA titania can also be formed by introducing color centers inside the material $[45,57]$. This defect induced doping can be produced either by heat treatment of $\mathrm{TiO}_{2}$ in vacuum 45 or inert gas environments or by intercalation of small cations $\left(\mathrm{H}^{+}, \mathrm{Li}^{+}\right.$, etc.) into the 46 lattice. In some cases, $\mathrm{O}_{2}$ is released from the material and $\mathrm{Ti}^{3+}$ centers are formed. Very 
recently, hydrogenation has been demonstrated as a very effective route to engineer the surface of anatase $\mathrm{TiO}_{2}$ nanoparticles with an amorphous layer which, instead of inducing detrimental recombination effects, resulted in the marked extension of the optical absorption to the infrared range and remarkable enhancement of solar-driven photocatalytic activity [180].

\section{Oxidation chemistry, the reactive oxygen species generated and their subsequent reaction pathways.}

\subsection{Reactive oxygen species and reaction pathways in $\mathrm{VLA} \mathrm{TiO} \mathrm{O}_{2}$ photocatalysis}

As a model, the reaction pathways of visible light-induced photocatalytic degradation of acid orange 7 (AO7) in the presence of $\mathrm{TiO}_{2}$ has been investigated [181], monitoring the formation and the fate of intermediates and final products in solution and on the photocatalyst surface as a function of irradiation time. It was observed that the intensity of the chromophore band of AO7 reduced exponentially with time and disappeared after about $60 \mathrm{~h}$. The intensities of the absorbance peaks related to the naphthalene and benzene rings in $\mathrm{AO} 7$ decreased with a slower rate compared to that of decolorization of the solution during the first $60 \mathrm{~h}$. After complete decolorization, the absorbance due to the naphthalene and benzene rings remained constant. This observation confirmed that in the absence of colored compounds on the photocatalyst surface, visible light cannot effectively degrade fragments containing the benzene and naphthalene rings produced by the cleavage of the dye molecule. It should be noted that AO7 solution was stable under visible light without $\mathrm{TiO}_{2}$, and that the $\mathrm{TiO}_{2}$ suspension was unable to initiate the dye degradation in the dark. Both visible light and $\mathrm{TiO}_{2}$ particles were indispensable for the degradation of $\mathrm{AO} 7$ in aqueous solution. During the irradiation of $\mathrm{AO}^{-\mathrm{TiO}_{2}}$ suspension with visible light different intermediates such as compounds containing a naphthalene ring, phthalic derivatives, aromatic acids, and aliphatic acids were identified. In addition, the evolution of inorganic ions such as sulfate, nitrate, nitrite, and ammonium ions were monitored during the irradiation by visible light.

By using appropriate quenchers, the formation of oxidative species such as singlet oxygen, superoxide, and hydroperoxide radicals and their role in the degradation of the dye molecules during illumination was studied [181]. It was observed that in the presence of 1, 4-benzoquinone (BQ), which is a superoxide quencher and a good electron acceptor [120], both photodegradation and formation of hydrogen peroxide were completely suppressed. This indicates that the superoxide radical is an active oxidative intermediate. Addition of sodium azide, which is a singlet oxygen quencher [182] and may also interact with hydroxyl radical [183], initially did not significantly affect the degradation of AO7 but the inhibition became important after $40 \mathrm{~min}$, indicating the delayed formation of singlet oxygen and possibly hydroxyl radical species. Formation of hydrogen peroxide was also suppressed in the presence of this inhibitor. Similar results were obtained by addition of 1,4-diazabicyclo[2,2,2]-octane (DABCO) [184], which is also a singlet oxygen quencher. The important point of the work in [181] is that when complete decolorization of the solution was achieved, the formation of active oxidation species and

46 hydrogen peroxide stopped, the oxidation reactions ceased and the concentrations of 
intermediates remained constant. This is because only in the presence of visible light absorbing compounds, the formation of oxidizing species was possible.

In a visible light/sensitizer/ $/ \mathrm{TiO}_{2}$ system, oxygen is indispensable in order to generate active oxygen radicals [185]. The role of dissolved oxygen and active species generated in the photocatalytic degradation of phenol was investigated by using a polymer sensitized $\mathrm{TiO}_{2}$ under visible light [186]. The experimental results showed that the photocatalytic degradation of phenol was almost stopped under nitrogen atmosphere. Therefore, oxygen is very important in photocatalytic reactions induced by visible light and it acts as an efficient electron scavenger. In this system, the degradation of phenol gradually decreased by increasing sodium azide concentration. This indicated that singlet oxygen was generated under visible light irradiation. Singlet oxygen can degrade phenol directly to about 40 percent which is due to its high energy level $\left(22.5 \mathrm{kcal} \mathrm{mol}^{-1}\right)$. In addition, singlet oxygen can be measured by phosphorescence in near IR as a direct method of detection. There is a range of different fluorescence or spin-trap probes for indirect measurements of singlet oxygen and/or superoxide. The spin-trap 2,2,6,6tetramethyl-4-piperidone- $N$-oxide (TEMP) is generally used as a probe for singlet oxygen in EPR studies. The reactions of TEMP with singlet oxygen yields a stable radical adduct [187]. Another useful spin trap system is the 5,5 dimethylpyrrolineloxide (DMPO) [188190]. Monitoring intermediate 5,5 dimethylpyrrolineloxide (DMPO)-OH ${ }^{\circ}$ radicals formed in the suspension during illumination [186] is done by its characteristic 1:2:2:1 quartet EPR spectrum and provides evidence of hydroxyl radicals in the system. In addition, some alcohols are commonly used as diagnostic tools for hydroxyl radical mediated mechanisms [191,192]. The degradation of phenol by adding i-PrOH or MeOH was decreased by about 60 percent which indicated that both of them seriously inhibited the photocatalytic degradation of phenol [186]. This confirmed that hydroxyl radicals were the predominant active species in this system, but did not probe the mechanism of hydroxyl radical formation.

\subsection{Photoelectrochemical methods for determining visible light activity}

If the photocatalytic material is immobilized onto an electrically conducting supporting substrate, one can use this electrode in a photoelectrochemical cell to measure properties including the band gap energy, flat band potential, dopant density, kinetics of hole and electron transfer, and the energies of dopant levels. If one examines the current-potential response under potentiometric control, for an n-type semiconductor e.g. $\mathrm{TiO}_{2}$, in the dark no significant anodic (positive) current is observed because there are essentially no holes in the valence band. When irradiated with light equal to the band gap energy, electrons are promoted to the conduction band, leaving positive holes in the valence band, and an increase is observed in the anodic current at potentials more positive that the flat band potential $E_{\mathrm{fb}}$. The difference between the current observed in the light and that in the dark is called the photocurrent $\left(J_{\mathrm{ph}}\right)$ and it is a measure of the hole-transfer rate at the SCelectrolyte interface. At the flat band potential, no net current is observed as all charge carriers recombine. For a p-type semiconductor, the situation is reversed and an increase in cathodic current is observed under band gap irradiation for potentials more negative

46 than $E_{\mathrm{fb}}$. If a monochromator is used along with a polychromatic source e.g. xenon, to 
irradiate the electrode one can determine the spectral photocurrent response and the incident photon to current conversion efficiency (IPCE).

where $J_{\mathrm{ph}}$ is the photocurrent density $\left(\mathrm{A} \mathrm{cm} \mathrm{cm}^{-2}\right), I_{0}$ is the incident light flux (moles of photons s $\left.\mathrm{cm}^{-1}\right)$ and $F$ is Faraday's constant $\left(\mathrm{C} \mathrm{mol}^{-1}\right)$. For an n-type semiconductor, this is the quantum efficiency for hole-transfer to the electrolyte. The maximum wavelength at which photocurrent is observed will correlate to the band gap energy for the material. Therefore, the visible light activity can be confirmed by simply using a light source with the desired emission spectrum to excite the electrode while monitoring the current as a function of applied potential. For example, Hamilton et al., [193] compared the spectral IPCE response between $\mathrm{TiO}_{2}$ and $\mathrm{WO}_{3}$ for the photooxidation of water (Figure 10). $\mathrm{WO}_{3}$ shows some activity in the visible with onset potential for anodic current positive relative to that observed for $\mathrm{TiO}_{2}$.

In detailed work concerning the photoelectrochemical investigation of metal ion doped $\mathrm{TiO}_{2}$, Hamilton et al found that in all cases doping resulted in a decrease of the photocurrent response under solar simulated illumination [194]. However, a sub-band gap response (visible light activity) was observed for some samples. The sub-band gap photocurrent was potential dependent and could be correlated to oxygen vacancy states below the conduction band. The primary band-gap photocurrent response was decreased by the addition of metal ion dopants, which act as charge-carrier recombination centres, and the sub-band gap photocurrent was only a very small fraction of the band-gap photocurrent.

Nakamura et al., used photoelectrochemical methods to investigate the mechanism of visible light activity for $\mathrm{N}$-doped $\mathrm{TiO}_{2}$ powder prepared by both wet and dry methods [195]. The powder was immobilised on FTO glass by spin coating of a colloidal suspension (N-doped $\mathrm{TiO}_{2} /$ water/acetylacetone/ $\mathrm{HNO}_{3} /$ Triton-X 100 ) followed by sintering at $400^{\circ} \mathrm{C}$. Photocurrents for undoped and $\mathrm{N}$-doped $\mathrm{TiO}_{2}$ film electrodes were measured as a function of wavelength, using a $350 \mathrm{~W}$ xenon lamp and a monochromator. The $\mathrm{N}$-doped $\mathrm{TiO}_{2}$ films gave a measurable IPCE\% beginning around $525 \mathrm{~nm}$ (increasing with decreasing wavelength), whereas the undoped $\mathrm{TiO}_{2}$ began to show a small IPCE\% around $425 \mathrm{~nm}$. To probe the mechanism further, they measured the IPCE\% in the presence of different reductants (hole acceptors). Their basic theory was that those species with an oxidation potential more negative than the $\mathrm{N}-2 \mathrm{p}$ level can be oxidised by holes in this inter-band gap state $(0.75 \mathrm{eV}$ above the valence band) thus giving rise to an increase in the measured IPCE\%, while those species with an oxidation potential more positive than the N-2p level cannot be oxidised by this state and therefore, no increase in IPCE\% will be observed. They found that all reductants used caused an increase in the UV IPCE\%, however, only I' and hydroquinone gave an increase in the visible IPCE\% (Figure 11). Doping with $\mathrm{N}$ will give rise to a (occupied) mid-gap (N-2p) level slightly above the top of the $(\mathrm{O}-2 \mathrm{p})$ valence band and visible-light illumination will generate 
valence band. The differences in the IPCE enhancement between UV and visible illumination can be attributed to differences in the reactivity of these holes (Figure 12). The measurement of the photocurrent should distinguish the above two oxidation processes because the photocurrent largely increases if a direct reaction with photogenerated holes occurs, whereas it there should be no difference observed if an indirect reaction via the intermediates of water photooxidation occurs. Nakamura et al., suggested that an increase in IPCE is not observed with the addition of $\mathrm{SCN}^{-}$or $\mathrm{Br}^{-}$ because large reorganisation energies are required for the electron transfer reactions. Therefore, simply assuming the photocurrent (or reactivity) is only related to the redox potential of the reductant (hole acceptor) is not adequate for explaining visible light activity. Furthermore, photocurrent was observed under visible light irradiation for the photo-oxidation of water (no hole acceptor present) and the redox potential for the $\left(\cdot \mathrm{OH} / \mathrm{H}_{2} \mathrm{O}\right)$ is more positive than the mid-gap $\mathrm{N}-2 \mathrm{p}$ level. Nakamura et al. reported that water photooxidation on $\mathrm{n}-\mathrm{TiO}_{2}$ (rutile) is not initiated by the oxidation of the surface $\mathrm{OH}$ group (Ti-OHs) with photogenerated holes $\left(\mathrm{h}^{+}\right)$, but rather initiated by a nucleophilic attack of an $\mathrm{H}_{2} \mathrm{O}$ molecule (Lewis base) to a surface hole (Lewis acid), accompanied by bond breaking.

$$
[\mathrm{Ti}-\mathrm{O}-\mathrm{Ti}]_{\mathrm{s}}+\mathrm{h}^{+}+\mathrm{H}_{2} \mathrm{O} \rightarrow[\mathrm{Ti}-\mathrm{O} \cdot \mathrm{HO}-\mathrm{Ti}]_{\mathrm{s}}+\mathrm{H}^{+}
$$

The latter will not have any direct relation with the redox potential such as $\mathrm{E}_{\mathrm{eq}}\left(\cdot \mathrm{OH} / \mathrm{H}_{2} \mathrm{O}\right)$ but will have a strong relation with the basicity of $\mathrm{H}_{2} \mathrm{O}$ or the energy of an intermediate radical [Ti-O $\cdot \mathrm{HO}-\mathrm{Ti}]_{\mathrm{s}}$ that is roughly giving the activation energy for the reaction. They concluded that the observed photocurrent in the presence of reductants strongly depends on the reaction mechanism of oxidation and more knowledge is needed concerning the mechanism.

Beranek and Kisch reported the photoelectrochemical response of $\mathrm{N}$-doped $\mathrm{TiO}_{2}$ prepared by heating anodized titanium sheets and urea to $400^{\circ} \mathrm{C}$ [196]. The resulting material consisted of a nitrogen-rich surface layer on the top of a nitrogen-poor core. The $\mathrm{TiO}_{2}-\mathrm{N}$ thin films exhibit photocurrents in the visible up to $700 \mathrm{~nm}$ due to the presence of occupied nitrogen-centered surface states above the valence band edge (Figure 13). The photocurrent transients significantly differed from those observed for undoped $\mathrm{TiO}_{2}$ films and this could be explained by increased electron-hole recombination in $\mathrm{TiO}_{2}-\mathrm{N}$ through these surface states. The addition of iodide partially suppressed the recombination due to hole scavenging. The flat band potential was determined by open circuit photopotential measurements and was anodically shifted by $+0.2 \mathrm{~V}$ to $-0.35 \mathrm{~V}$ (NHE) for $\mathrm{TiO}_{2}-\mathrm{N}$ as compared to the undoped $\mathrm{TiO}_{2}$.

Photoelectrochemical measurements can contribute significantly to the understanding of the mechanisms involved in the visible light activity of doped $\mathrm{TiO}_{2}$ and other photocatalytic materials and can be combined with direct measuring the spectral dependence of the quantum efficiency for different pollutants [197]. More research is required to fully elucidate the mechanisms involved.

\section{Environmental Applications of $\mathrm{VLA} \mathrm{TiO}_{2}$}


Conventional $\mathrm{TiO}_{2}$ has been extensively studied for water treatment and air purification and it is well known to be an effective system to treat several hazardous compounds in contaminated water and air. Some focus is given nowadays to VLA $\mathrm{TiO}_{2}$-based photocatalysis and its application towards remediation of regulated and emerging contaminants of concern.

Senthilnatan and Philip reported the degradation of lindane, an organochlorine pesticide, under visible light with different $\mathrm{TiO}_{2}$ photocatalyst [198]. $\mathrm{N}$-doped $\mathrm{TiO}_{2}$, synthesized with different nitrogen containing organic compounds in a modified sol-gel method, showed better photocatalytic activity compared to other metal ions-doped $\mathrm{TiO}_{2}$ and Evonik P25-TiO 2 . Several phenoxyacid herbicides (i.e., mecropop, clopyralid) were photocatalytically transformed employing $\mathrm{Fe}-, \mathrm{N}$-doped anatase and rutile $\mathrm{TiO}_{2}$ as well as undoped anatase and rutile $\mathrm{TiO}_{2}$ under visible light irradiation [199]. Degradation rates of all pesticides employed were higher with $\mathrm{N}$-doped anatase $\mathrm{TiO}_{2}$ and the difference in photoreactivity was directly related to the molecular structure of the herbicide and its interaction with the radical species produced. 2,4-dichlorophenoxyacetic acid (2,4-D) is a widely used herbicide and found in surface and ground water from agricultural runoffs. $\mathrm{Ag} / \mathrm{TiO}_{2}$ photocatalyst, hydrothermally synthesized with template-assisted methods, effectively degraded 2,4-D under visible light [200]. Increasing Ag content diminished the photoreactivity of $\mathrm{TiO}_{2}$ under the conditions tested. Also, increase in $\mathrm{Ag}$ concentration also increase the amount of brookite phase formed, affecting this the photoresponse of $\mathrm{Ag} / \mathrm{TiO}_{2}$.

The diverse group of substances, which are commonly detected at low concentration in the aqueous media and often are difficult to quantitatively remove from the water by conventional water treatment processes, can produce important damages in human health and in the aquatic environment, even at low concentrations. Some of these contaminants can have endocrine disruption effects in humans and aquatic organisms and the consequences of their exposure to organisms can go from developmental problems to reproduction disorders. Wang and Lim developed several nitrogen and carbon doped $\mathrm{TiO}_{2}$ via solvothermal method for the degradation of bisphenol-A under visible lightemitting diodes. The use of alternative visible light, such as light-emitting diodes, LEDs, provides several advantages, including energy efficiency, flexibility and extended lifetime [201]. All the synthesized $\mathrm{CN}-\mathrm{TiO}_{2}$ photocatalysts exhibited higher removal efficiencies for bisphenol-A than reference materials. In all cases, the highest extend of removal and mineralization was with emitting white light followed by blue, green and yellow light, in agreement with the adsorption edge of the doped $\mathrm{TiO}_{2}$ materials. Neutral $\mathrm{pH}$ seems to be favorable for the degradation of this EDC in water. The presence of inorganic ions in the water matrix had different effects towards the degradation of bisphenol-A. Chloride, nitrate and sulfate ions partially inhibited the photocatalytic process while silica and bicarbonate scavenged to a greater extend the degradation of bisphenol-A under the conditions tested. In a related study, nitrogen-doped $\mathrm{TiO}_{2}$ hollow 
spheres in a titania sol followed by heat treatment, were evaluated for the photocatalytic degradation of bisphenol-A under different light emitting LEDs [202]. NHS exhibited higher performance towards the degradation of bisphenol-A compared to undoped $\mathrm{TiO}_{2}$ hollow spheres and $\mathrm{TiO}_{2}$ powder. Nevertheless, the degree of degradation of bisphenol-A decreased from blue LED $(\lambda=465 \mathrm{~nm})$ to yellow LED $(\lambda=589 \mathrm{~nm})$ light, which is in agreement with Wang and Ling. Several intermediates detected were found to be reported previously with $\mathrm{UV}$-irradiated $\mathrm{TiO}_{2}$, thus following similar degradation pathways. Composite materials, such as nitrogen-doped $\mathrm{TiO}_{2}$ supported on activated carbon (N$\mathrm{TiO}_{2} / \mathrm{AC}$ ), have also been tested and proven to have a dual effect on the adsorption and photocatalytic degradation of bisphenol-A under solar light [203]. Even though the maximum adsorption capacity for bisphenol- $\mathrm{A}$ was reduced for $\mathrm{N}-\mathrm{TiO}_{2} / \mathrm{AC}$ compared to virgin $\mathrm{AC}$ at $\mathrm{pH}$ 3.0, higher photodegradation efficiencies were found for $\mathrm{N}-\mathrm{TiO}_{2} / \mathrm{AC}$ than with $\mathrm{N}-\mathrm{TiO}_{2}$ and undoped $\mathrm{TiO}_{2}$ only at different excitation wavelengths.

Visible light active $\mathrm{TiO}_{2}$ photocatalysts have also been employed for the photocatalytic degradation of cyanotoxins, in particular, the hepatotoxin microcystin-LR (MC-LR). MCLR is a contaminant of emerging concern, highly toxic and frequently found cyanotoxin in surface waters. $\mathrm{N}-\mathrm{TiO}_{2}$ photocatalyst, described in section 2.1 as a one step process synthesis with DDAC as pore template and nitrogen dopant, efficiently degraded MC-LR under visible light. $\mathrm{N}-\mathrm{TiO}_{2}$ calcined at $350^{\circ} \mathrm{C}$ showed the highest MC-LR degradation efficiency and an increase in calcination temperature resulted in a decrease of the photocatalytic activity of $\mathrm{N}-\mathrm{TiO}_{2}$ towards the removal of MC-LR. N-F co-doped $\mathrm{TiO}_{2}$ nanoparticles synthesized from a modified sol-gel method were also applied for the degradation of MC-LR. Synergistic effects were observed with co-doped material, specifically in the photocatalytic improvement of MC-LR degradation at wavelengths > $420 \mathrm{~nm}$, compared to nitrogen and fluorine only doped $\mathrm{TiO}_{2}$ and undoped $\mathrm{TiO}_{2}$. A pH dependence was observed in the initial degradation rates of MC-LR where acidic conditions $(\mathrm{pH}$ 3.0) were favorable compare to higher $\mathrm{pH}$ values [116]. When immobilizing $\mathrm{NF}^{-\mathrm{TiO}_{2}}$ on glass substrate, different fluorosurfactant molar ratios in the sol were tested and the efficiency of the synthesized photocatalytic films was evaluated for MC-LR removal. When increasing the fluorosurfactant ratio, higher MC-LR degradation rates were observed at $\mathrm{pH} 3.0$ [117]. This is due to the effective doping of nitrogen and fluorine and the physicochemical improvements obtained with different surfactants loadings in the sol. Rhodium doped $\mathrm{TiO}_{2}$, at high photocatalyst concentration, was shown to completely remove MC-LR under visible light conditions [204]. Much less active visible light photocatalyst for $\mathrm{MC}-\mathrm{LR}$ degradation were $\mathrm{TiO}_{2}-\mathrm{Pt}(\mathrm{IV})$ and carbon doped $\mathrm{TiO}_{2}[204]$.

Volatile organic compounds (VOCs) are hazardous air pollutants that can be emitted into the atmosphere by a wide variety of industrial processes and cause adverse effects on the human nervous system, via breathing. A bifunctional photocatalyst, obtained from nitrogen-doped and platinum-modified $\mathrm{TiO}_{2}\left(\mathrm{Pt} / \mathrm{TiO}_{2-\mathrm{x}} \mathrm{N}_{\mathrm{x}}\right)$, was proven effective for the decomposition of benzene and other persistent VOCs under visible light irradiation in a $\mathrm{H}_{2}-\mathrm{O}_{2}$ atmosphere [205]. The doping of nitrogen and the incorporation of platinum played an important role in the enhancement of the visible light photocatalytic activity, mainly on the interfacial electron transfer at the surface of the photocatalyst. Ethyl 
benzene and $o, m, p$-xylenes were removed by employing $\mathrm{N}-\mathrm{TiO}_{2}$ at indoor air levels in an annular reactor even under typical humidified environments found indoor. Both low stream flow rates and low hydraulic diameter in the reactor are beneficial for higher degradation efficiencies. Composite $\mathrm{N}-\mathrm{TiO}_{2} /$ zeolite was investigated for the removal of toluene from waste gas. High porosity and effective visible light activation of the composite material gave a synergistic effect on the photocatalytic degradation of toluene compared to bare $\mathrm{TiO}_{2}$ /zeolite [206]. This process was coupled to a biological treatment for further mineralization of toluene.

\subsection{Water disinfection with VLA photocatalysis}

Over the past ten years solar activated photocatalytic disinfection of water has received significant attention with research focus moving from laboratory studies to pilot experimentation [207]. Visible light-active (VLA) doped $\mathrm{TiO}_{2}$ has also been investigated for a range of disinfection applications, including water purification. Twenty years after Matsunaga et al., published the first paper detailing with photocatalytic disinfection using a range of organisms and $\mathrm{TiO}_{2} / \mathrm{Pt}$ particles [208], Yu et al., described disinfection of the Gram positive bacterium Micrococcus lylae using sulfur-doped titanium dioxide exposed to $100 \mathrm{~W}$ tungsten halogen lamp fitted with a glass filter to remove wavelengths less than $420 \mathrm{~nm}$ [209]. They reported $96.7 \%$ reduction in viable organisms following 1 hour treatment in a slurry reactor containing $0.2 \mathrm{mg} / \mathrm{mL} \mathrm{S}$-doped- $\mathrm{TiO}_{2}(1.96 \mathrm{At} \%)$, prepared via a copolymer sol-gel method. ESR measurements, using DMPO, confirmed the formation of hydroxyl radicals which were described as the reactive oxygen species responsible for the observed disinfection. Early work with $\mathrm{N}$-doped $\mathrm{TiO}_{2}$, using Escherichia coli (E. coli) as the target organism, reported superior photocatalytic activity in comparison to Evonik P25 under solar light exposure [210]. Li et al., reported enhanced disinfection of E. coli when VLA TiON was co-doped with carbon [211]. They attributed the additional biocidal effect to increased visible light absorption.

Mitoraj et al., describe VLA photocatalytic inactivation of a range of organisms, including Gram negative and Gram positive bacteria (E. coli, Staphylococcus aureus and Enterococcus faecalis) and fungi (Candida albicans, Aspergillus niger), using carbondoped $\mathrm{TiO}_{2}$ and $\mathrm{TiO}_{2}$ modified with platinum(IV) chloride complexes in both suspension and immobilized reactor configurations [212]. The order of disinfection followed that commonly observed, whereby organisms with more significant cell wall structures proved more resistant to the biocidal species produced by photocatalysis: $E$. coli $>S$. aureus $=$ E. faecalis. $C$. albicans and A. niger were much more resistant than the bacterial organisms examined. E. coli inactivation has also been reported using $\mathrm{S}$-doped $\mathrm{TiO}_{2}$ films, produced via atmospheric pressure chemical vapor deposition, upon excitation with fluorescent light sources commonly found in indoor healthcare environments [213]. A palladium-modified nitrogen-doped titanium oxide (TiON/PdO) photocatalytic fiber was used for the disinfection of MS2 phage by Li et al. [214]. Under dark conditions, significant virus adsorption was measured (95.4-96.7\%) and upon subsequent illumination of the samples with visible light $(>400 \mathrm{~nm})$ for 1 hour additional virus

46 removal of 94.5-98.2\% was achieved (the overall virus removal was 3.5-log from an 
initial concentration of $\sim 1 \times 10^{8}$ plaque forming units). EPR measurements were used to confirm the presence of ${ }^{\circ} \mathrm{OH}$ radicals. It was suggested that ${ }^{\circ} \mathrm{OH}$ radicals were formed via a reduction mechanism involving dissolved oxygen (Eq. 3.1 and 3.2).

$$
\begin{aligned}
& \mathrm{O}_{2}{ }^{--}+\mathrm{O}_{2}{ }^{-}+2 \mathrm{H}^{+} \rightarrow \mathrm{H}_{2} \mathrm{O}_{2}+\mathrm{O}_{2} \\
& \mathrm{H}_{2} \mathrm{O}_{2}+\mathrm{e}^{-}{ }_{\mathrm{CB}} \rightarrow \mathrm{OH}+\mathrm{OH}^{-}
\end{aligned}
$$

$\mathrm{Wu}$ et al., produced titanium dioxide nanoparticles co-doped with $\mathrm{N}$ and $\mathrm{Ag}$ and investigated the efficiency of photocatalytic innactivation of $E$. coli under visible light irradiation $(\lambda>400 \mathrm{~nm})$ [215]. A 5-log inactivation was observed after ca. $30 \mathrm{~min}$ irradiation, although disinfection was observed in the dark controls due to the biocidal properties of $\mathrm{Ag}$ ions. ESR studies demonstrated a significant increase in ${ }^{\circ} \mathrm{OH}$ production on the $\mathrm{Ag}, \mathrm{N}$-doped $\mathrm{TiO}_{2}$. Interactions between the $\mathrm{ROS}$ and $E$. coli resulted in physical damage to the outer membrane of the bacterial cell, structural changes within the plasma membrane were also observed. Similar structural and internal damage was suggested to be responsible for the inactivation in Pseudomonas aeruginosa when exposed to sunlight in the presence of $\mathrm{Zr}$ doped $\mathrm{TiO}_{2}$ [216].

Some of the most comprehensive studies on $\mathrm{VLA} \mathrm{TiO}_{2}$ disinfection have been undertaken by the Pulgarin group at EPFL, Switzerland. Commercial titania powders (Tayca TKP101, TKP102 and Evonik P25) were mechanically mixed with thiourea and urea to produce $\mathrm{S}$-doped, $\mathrm{N}$-doped and $\mathrm{S}$, $\mathrm{N}$ co-doped $\mathrm{VLA} \mathrm{TiO}_{2}$ powders [217-220]. Various thermal treatments produced both interstitial and substitutional N-doping and cationic and anionic S-doped Tayca powders; thiourea treated P25 exhibited low level interstitial N-doping and anionic S-doping. Suspension reactor studies using E. coli showed that the doped Tacya materials were slightly less active that the non-doped powders during UV excitation, however, under visible light excitation $(400-500 \mathrm{~nm})$ the $\mathrm{N}, \mathrm{S}$ co-doped powders outperformed the undoped powders, with those annealed at $400^{\circ} \mathrm{C}$ resulting in 4-log E. coli inactivation following $75 \mathrm{~min}$ treatment [216]. The authors concluded that the nature of the doping (substitutional or interstitial $\mathrm{N}$-doping and cationic or anionic S doping), surface hydroxylation and the particle size play important roles in the generation of biocidal ROS. In experiments with N, S co-doped Evonik P25, a 4- $\log E$. coli inactivation was observed following $90 \mathrm{~min}$ exposure to visible light $(\lambda=$ $400-500 \mathrm{~nm}$ ) [217]. The authors proposed that upon UVA excitation the ${ }^{\circ} \mathrm{OH}$ radical is the most potent ROS, however; under visible excitation a range of ROS could be produced through reduction of molecular oxygen by conduction band electrons (superoxide radical anion, hydrogen peroxide and hydroxyl radicals), with singlet oxygen likely to be produced by the reaction of superoxide radical anion with localised $\mathrm{N}$ and $\mathrm{S}$ mid band-gap states [217]. Further mechanistic studies using N, S co-doped Tayca titania with phenol and dichloroacetate (DCA) as model probes, demonstrated complete E. coli disinfection but only partial phenol oxidation and no degradation of DCA under visible excitation [218]. Subsequent ESR experiments confirmed the production of both singlet oxygen and superoxide radical anion.

More recently, Rengifo-Herrera and Pulgarin investigated the use of N, S co-doped titania for disinfection under solar simulated exposure [221]. Using the photocatalyst in 
suspension, E. coli inactivation was observed with all doped and un-doped materials, however, the most efficient catalyst was undoped Evonik P25. Although the production of singlet oxygen and superoxide radical anion may contribute to the biocidal activity observed in N, S co-doped P25, under solar excitation the main species responsible for $E$. coli inactivation was the hydroxyl radical produced by the UV excitation of the parent material (Figure 14). This finding clearly demonstrates that production of VLA photocatalytic materials for disinfection applications requires careful consideration of the ROS being generated and detailed experiments to show potential efficacy of new VLA materials.

\section{Assessment of VLA photocatalyst materials}

\subsection{Standardization of test methods}

Many researchers working in the field of photocatalysis are frustrated by the difficulty posed when attempting to compare results published by different laboratories. Long ago it was proposed that the extent of the difference in the photocatalytic experimental systems used could be identified if each group reported the initial rate of a standard test pollutant [222-225]. In the establishment of a standard test system, one of the most important factors is the determination of quantum yield or quantum efficiency. The overall quantum yield for a photoreaction $\left(\Phi_{\text {overall }}\right)$ is defined as follows [23],

$$
\Phi_{\text {overall }}=\text { rate of reaction } / \text { rate of absorption of radiation }
$$

In heterogeneous semiconductor photocatalysis, the $\Phi_{\text {overall }}$ is very difficult to measure due to the problems distinguishing between absorption, scattering and transmission of photons. A more practical term, the photonic efficiency $(\xi)$, sometimes referred to as $\Phi_{\text {apparent, }}$ has been suggested:

$$
\xi=\text { rate of reaction / incident monochromatic light intensity }
$$

where the rate of absorption of radiation is simply replaced by the light intensity incident upon the reactor (or just inside the front window of the photoreactor). It is much simpler to determine the photonic efficiency than the true quantum yield. In addition the photonic efficiency is also a more practical quantity in terms of the process efficiency as the fraction of light scattered or reflected by semiconductor dispersion (or immobilized film) may be $13 \%-76 \%$ of the incident light intensity. Thus the difference between $\Phi_{\text {overall }}$ and $\xi$ may be significant. In research and practical applications, polychromatic light sources will be employed, and therefore one must replace $\xi$ with the Formal Quantum Efficiency (FQE);

$$
\mathrm{FQE}=\text { rate of reaction / incident light intensity }
$$

For multi-electron photocatalytic degradation processes, the FQE will be much less than unity; unless a chain reaction is in operation. Therefore, it is most important that researchers specifically report their methods of quantum efficiency determination. 
The solar spectrum contains only a small fraction of UV (4-5\%) and this somewhat limits the application of wide band (UV absorbing) semiconductors, e.g. $\mathrm{TiO}_{2}$, for solar energy driven water treatment. Even with good solar irradiance, the maximum solar efficiency achievable can only be 5\%. The apparent quantum efficiency for the degradation of organic compounds in water is usually reported to be around $1 \%$ with UV irradiation, under optimum experimental conditions. Therefore, one can only reasonably expect an overall solar efficiency of around $0.05 \%$ for photocatalytic water treatment employing a UV band gap semiconductor.

A number of test systems have been proposed to assess the relative photocatalytic efficiency for the degradation of organic pollutants in water. For example, Mills et al. [225], suggested phenol / Evonik P25 / $\mathrm{O}_{2}$ or 4-chlorophenol / Evonik P25 / $\mathrm{O}_{2}$. In such a standard system, the experimental parameters would be defined, e.g. [4-chlorophenol] $=$ $10^{-3} \mathrm{~mol} \mathrm{dm}^{-3},\left[\mathrm{TiO}_{2}\right]=500 \mathrm{mg} \mathrm{dm}^{-3},\left[\mathrm{O}_{2}\right]=1.3 \times 10^{-3} \mathrm{~mol} \mathrm{dm}^{-3}\left(\mathrm{P}_{\mathrm{O} 2}=1 \mathrm{~atm}\right), \mathrm{pH} 2, \mathrm{~T}=$ $30^{\circ} \mathrm{C}$. A comparison of the rate of the photocatalytic reaction under test with that obtained for the standard test system would provide some idea of the efficiency of the former process and allow some degree of comparison of results between groups. Other researchers [222-226] have suggested the use of relative photonic efficiencies $\left(\xi_{r}\right)$, where both (initial) destruction rates of the tested pollutant and phenol as a model one with common molecular structure are obtained under exactly the same conditions.

$$
\xi_{r}=\text { rate of disappearance of substrate / rate of disappearance of phenol }
$$

However, Ryu and Choi reported that the photocatalytic activities can be represented in many different ways, and even the relative activity order among the tested photocatalysts depends on what substrate is used [227]. They tested eight samples of $\mathrm{TiO}_{2}$ (suspension reactor) and each showed the best activity for at least one test-substrate. This highly substrate-specific activity of $\mathrm{TiO}_{2}$ photocatalysts hinders the relative comparison of different catalyst materials. They proposed that a multi-activity assessment should be used for comparison of photocatalytic activity, i.e. four substrates should be examined: phenol, dichloroacetic acid (DCA), tetramethyl ammonium (TMA), and trichloroethylene (TCE) to take the substrate-specificity into account. They represent the aromatic, anionic, cationic, and chlorohydrocarbon compounds, respectively, which are distinctly different in their molecular properties and structure.

The problems relating to the measurement of photocatalytic efficiency is further complicated when researchers attempt to compare the activities of 'visible light active' materials. Although visible light activity is in itself of fundamental interest, the test regime should consider the proposed application of the material. For example, if the application is purely a visible light driven process e.g. self-cleaning surfaces for indoor applications, then a visible light source should be utilized for the test protocol. However, if the application is towards a solar driven process then simulated solar light or ideally real sun should be utilized for the test protocol. Many researchers investigate visible light activity by using a polychromatic source, e.g. xenon, and cutting out the UV component with a filter. That is important when determining the visible only activity; however, it is 
important the experiments are also conducted with light which corresponds to the solar spectrum, including ca. 5\% UVA. When the UV activity of the material is good, this may outweigh any contribution from a relatively small visible light activity, hence the importance of photonic efficiency or FQE.

Doping of $\mathrm{TiO}_{2}$ may give rise to a color change in the material as a result of the absorption of visible light however; an increase in visible absorption, in principle, does not guarantee visible light induced activity. Photocatalytic reactions proceed through redox reactions by photogenerated positive holes and photoexcited electrons. No activity may be observed if, for example, all of these species recombined. Various photocatalytic test systems with different model pollutants/substrates have been reported. Dyes are commonly used as model pollutants, partly because their concentration can be easily monitored using visible spectrophotometry; however, because the dyes also absorb light in the visible range, the influence of this photo-absorption by dyes should be excluded for evaluation of the real photocatalytic activity of materials. According to Herrmann [228], a real photocatalytic activity test can be erroneously claimed if a non-catalytic sidereaction or an artefact occurs. Dye decolourization tests can represent the most "subtle pseudo-photocatalytic" systems, hiding the actual non-catalytic nature of the reaction involved. An example of this dye sensitised phenomenon was reported with the apparent photocatalytic "disappearance" of indigo carmine dye [229]. The indigo carmine was totally destroyed by UV-irradiated titania; however, its colour also disappeared when using visible light but the corresponding total organic carbon (TOC) remained intact. The loss of colour actually corresponded to a limited transfer of electrons from the photoexcited indigo (absorbing in the visible) to the $\mathrm{TiO}_{2}$ conduction band. This 'dye sensitization' phenomenon is well known and exploited in the 'Gratzel' dye sensitized photovoltaic cell [22]. A dye which has been used widely as a test substrate for photocatalytic activity is methylene blue. Indeed the degradation of methylene blue is a recommended test for photocatalytic activity in the ISO/CD10678 [230]. Yan et al., reported on the use of methylene blue as a test substrate to evaluate the VLA for $\mathrm{S}_{-} \mathrm{TiO}_{2}$ [231]. Two model photocatalysts were used, i.e. homemade $\mathrm{S}-\mathrm{TiO}_{2}$ and a commercial sample (Nippon Aerosil P-25) as a reference. Their results showed that a photo-induced reaction by methylene blue photo-absorption may produce results that could be mistaken to be evidence of visible-light photocatalytic activity. They suggested that dyes other than methylene blue should also be examined for their suitability as a probe molecule. Yan et al., used monochromatic light to determine the action spectrum enabling them to discriminate the origin of photoresponse by checking the wavelength dependence. However, most researchers simply use optical cut-off filters that transmit light above a certain wavelength. Yan et al., recommend the use of model organic substrates which do not absorb in the spectral region being used for excitation.

40

41

42

43

44

45

46

To complicate matters further, the photoreactor to be used in test reaction must be appropriate. It is good practice to compare any novel material with a relatively well established photocatalyst material, e.g. Evonik P25 [232]. The test system should utilize the catalyst in the same form - suspension or immobilized. Where suspension systems are employed, the catalyst must be well dispersed and an analysis of the particle size distribution should be undertaken. The optimum loading for each catalyst should also be 
determined. Where an immobilized catalyst system is employed, one must ensure that the reaction is not mass transfer limited otherwise the rate of degradation will simply be reflecting the mass transfer characteristics of the reactor. A high flow or a stirred tank system may be employed in an attempt to determine the intrinsic kinetics of the photocatalytic system [233].

Analysis of the literature concerning the development of visible light active photocatalytic materials for the destruction of organic pollutants in water shows that, while there has been enormous effort towards synthesis and characterisation of VLA materials, more attention has been paid to the photocatalysis test protocols. In the absence of a widely accepted standard test protocol, researchers should ensure the following, where possible: 1) the light source is appropriate with respect to the application and the emission spectrum is quantitatively determined, 2) more than one test substrate is used e.g. multi-activity assessment proposed by Ryu and Choi [227], and substrates absorbing light within the emission spectrum of the light source are avoided [230], 3) the reactor is well characterized i.e. for suspension systems the particle size distribution is determined, 4) the photoreactor is appropriate and well characterized in terms of mass transfer; and 5) the photonic efficiencies or FQEs are reported along with the emission spectrum of the illumination source. Research and development for solar driven water treatment should utilize experiments under simulated or real solar irradiation, not just visible light sources.

\subsection{Challenges in commercializing VLA photocatalysts}

Some VLA $\mathrm{TiO}_{2}$ photocatalytic products, like Kronos ${ }^{\circledR}$ VLP products, have already appeared in the market. Apart from the need for improvement on the photocatalytic efficiency, deactivation of $\mathrm{TiO}_{2}$ photocatalysts over time has proven to be an inherent obstacle of the material that needs to be considered when commercializing VLA photocatalysts., in general [234]. Deactivation occurs when partially oxidized intermediates block the active catalytic sites on the photocatalyst [235]. Gas phase deactivation is more predominant than the aqueous phase, because in the aqueous phase, water assists in the removal of reaction intermediates from the photocatalyst surface [236]. The photocatalytic degradation of many organic compounds also generates unwanted by-products, which may be harmful to human health [23]. Certain elements and functional groups contained in organic molecules have been found to strongly hinder the photocatalytic ability of $\mathrm{TiO}_{2}$ through deactivation. Peral and Ollis found that $\mathrm{N}$ or $\mathrm{Si}$ containing molecules may cause irreversible deactivation through the deposition of species that inhibit photoactive sites on the catalyst surface [237]. Carboxylic acids formed from alcohol degradation are also believed to strongly be adsorbed to the active sites of a catalyst and cause deactivation [23]. Strongly adsorbed intermediate species appear to commonly cause deactivation of a photocatalyst and it is certainly an area where further improvement is essential before $\mathrm{TiO}_{2}$ can be considered a viable option for continuous photocatalytic applications.

44

45

46

Several researchers have been studying regeneration methods for the $\mathrm{TiO}_{2}$ photocatalyst. Potential regeneration methods investigated include; thermal treatment $\left(<400{ }^{\circ} \mathrm{C}\right)$ in air 
[238], sonication with water and methanol [239], irradiating the catalyst under UV light while passing humid air over the surface [240] and exposing the catalyst to air rich with $\mathrm{H}_{2} \mathrm{O}_{2}$, both with and without UV light [236].

\section{Conclusions}

In this review, titanium dioxide is introduced as a promising semiconductor photocatalyst due to its physical, structural and optical properties under UV light. In order to be photoexcited under visible light and aim at solar-driven $\mathrm{TiO}_{2}$ photocatalysis, several synthesis methods have been successfully applied to achieve $\mathrm{VLA} \mathrm{TiO}_{2}$ photocatalysts. Non metal doping, in particular nitrogen doping, can be incorporated as substitutional or insterstitial state in the $\mathrm{TiO}_{2}$ lattice. Other non metals including carbon, fluorine and sulphur for doping and co-doping with nitrogen have been also investigated and shown visible light photo-induced activity. A variety of synthesis methods for noble metal and transition metal deposition, dye sensitization and coupling semiconductors have also extended the optical response of $\mathrm{TiO}_{2}$ into the visible region. The reactive oxygen species generated with VLA $\mathrm{TiO}_{2}$ under visible light indicate a different mechanism of photoactivation compared to UV light. The photocatalytic inactivation of a range of microorganisms has been explored using VLA $\mathrm{TiO}_{2}$. High log reductions were observed for common microorganisms, like E.coli, with metal and non-metal doped $\mathrm{TiO}_{2}$ under visible and solar light. Moreover, the application of $\mathrm{VLA}^{\mathrm{TiO}}{ }_{2}$ for the removal of persistent and contaminants of emerging concern in water treatment and air purification has been effective compared to conventional $\mathrm{TiO}_{2}$ under visible light. Therefore, these results are promising for further development of sustainable environmental remediation technologies, based on photocatalytic advanced oxidation processes driven by solar light as a renewable source of energy. Nevertheless, an effective assessment of VLA nanomaterials is needed to address several issues regarding test protocols, ensure true photocatalytic activity, and explore future commercialization of the material.

\section{Acknowledgments}

The authors wish to acknowledge financial support from NSF-Invest NI, Science Foundation Ireland (SFI) and NSF-CBET (Award 1033317) and the European Union's Seventh Framework Programme (FP7/2007-2013) under Grant Agreement 227017 ("Clean Water" collaborative project). We also wish to thank Dr. John Colreavy, Director of CREST, DIT Dublin Ireland (and the vice-chair of the photocatalytic COST action540), for supporting the research and reviewing the manuscript. 


\section{References}

1. N. T. Nolan, M. K. Seery, S. C. Pillai, J. Phys. Chem. C 113 (2009) 16151-16157.

2. Y. Hu, H.-L. Tsai, C.-L. Huangk, Eur. Ceram. Soc., 23 (2003) 691-696.

3. D. Nicholls, Complexes and First-Row Transition Elements, MacMillan Education, Hong Kong, 1974.

4. Y. Shao, D. Tang, J. Sun, Y. Lee, W. Xiong, China Particuology 2 (2004) 119123.

5. O. Carp, C. L. Huisman, A. Reller, Progress in Solid State Chem., 32 (2004) 33177.

6. X. Chen and S. S. Mao, Chem. Rev., 107(2007) 2891-2959.

7. X-Q. Gong and A. Selloni, Phys. Rev. B 76 (2007) 235307

8. A. Wisitsoraat, A. Tuantranont, E. Comini, G. Sberveglieri and W. Wlodarski, Thin Solid Films, 517 (2009) 2775-2780.

9. R. Asahi, Y. Taga, W. Mannstadt, A. J. Freeman, Phys. Rev. B 61 (2000) 74597465.

10. A. Amtout and R. Leonelli, Phys. Rev. B 51 (1995) 6842-6851.

11. M. Koelsch, S. Cassaignon, C. T. Thanh Minh, J.-F. Guillemoles, J.-P. Jolivet, Thin Solid Films, 451 (2004) 86-92.

12. M. R. Hoffmann, S. T. Martin, W. Choi, D. W. Bahnemann, Chem. Rev., 95 (1995) 69-96.

13. O.Carp, C. L. Huisman, A.Reller, Progress in Solid State Chem. 32 (2004) 33177.

14. M. A. Fox and M. T. Dulay, Chem. Rev. 93 (1993) 341-357.

15. Y. Wang, Y. Huang, W. Ho, L. Zhang, Z. Zou, S. Lee, J. Hazard. Mater., 169 (2009) 77-87.

16. C. Su, C.-M. Tseng, L.-F. Chen, B.-H. You, B.-C. Hsu and S.-S. Chen, Thin Solid Films, 498 (2006) 259-265.

17. A. Fujishima and K. Honda, Nature, 238 (1972) 37-38.

18. S. N. Frank and A. J. Bard, J. Am. Chem. Soc., 99 (1977) 303-304.

19. S. N. Frank and A. J. Bard, J. Phys. Chem., 81 (1977) 1484-1488.

20. J. Zhao, T. Wu, K. Wu, K. Oikawa, H. Hidaka, N. Serpone, Environ. Sci. Technol., 32 (1998) 2394-2400.

21. R. Wang, K. Hashimoto, A. Fujishima, M. Chikuni, E. Kojima, A. Kitamura, Nature, 388 (1997) 431-432.

22. B. O'Regan and M. Gratzel, Nature, 353 (1991), 737-739.

23. A. Mills and S. Le Hunte, J. Photochem. Photobiol. A, 108 (1997) 1-35.

24. P. Suppan, Chemistry and Light, Royal Society of Chemistry, Cambridge, 1994.

25. A. Testino, I. R. Bellobono, V. Buscaglia, C. Canevali, M. D'Arienzo, S. Polizzi, R. Scotti, F. Morazzoni, J. Am. Chem. Soc., 129 (2007) 3564-3575.

26. T. Tachikawa, M. Fujitsuka, T. Majima, J. Phys. Chem. C 111 (2007) 5259-5275.

27. P. D. Cozzoli, R. Comparelli, E. Fanizza, M. L. Curri, A. Agostiano, Mat. Sci. Eng. C 23 (2003) 707-713.

28. A. Hoffman, E. R. Carraway, M. Hoffman, Environ. Sci. Technol., 28 (1994) 776785 . 
29. C. A. Emilio, M. I. Litter, M. Kunst, M. Bouchard, C. Colbeau-Justin, Langmuir, 22 (2006) 3606-3613.

30. W. Choi, A. Termin, M. R. Hoffmann, J. Phys. Chem. B, 98 (1994) 13669-13679.

31. A. Sclafani, J. Phys. Chem., 100 (1996) 13655-13661.

32. J. Liqiang, Q. Yichun, W. Baiqi, L. Shudan, J. Baojiang, Y. Libin, F. Wei, F. Honggang, S. Jiazhong, Solar Energy Materials \& Solar Cells, 90 (2006) 17731787.

33. N. Serpone, J. Photochem. Photobiol. A, 104 (1997).

34. N. Serpone, D. Lawless, R. Khairutdinov, E. Pelizetti, J. Phys. Chem., 99 (1995).

35. J. Soria, J. C. Conesa, V. Augugliaro, L. Palmisano, M. Schiavello and A. Sclafani, J. Phys. Chem., 1991, 95.

36. J. C. Yu, J. G. Yu, K. W. Ho, Z. T. Jiang and L. Z. Zhang, Chem. Mater., 2002, 14.

37. Y. R. Do, K. Lee, K. Dwight and W. Wold, J. Sol. State Chem., 1994, 108.

38. J. Engweiler, J. Harf and A. Baiker, J. Catal., 1996, 159.

39. K. Vinodgopal and P. V. Kamat, Environ. Sci. Technol., 1995, 29.

40. A. J. Maira, K. L. Yeung, C. Y. Lee, P. L. Yue and C. K. Chan, J. Catal., 2000, 192.

41. Z. L. Xu, J. Shang, C. M. Liu, C. Kang, H. C. Guo and Y. G. Du, Mater. Sci. Eng. B, 1999, 63.

42. Y. Li, D.-S. Hwang, N. H. Lee and S.-J. Kim, Chem. Phys. Lett., 2005, 404.

43. J. Yu, H. Yu, B. Cheng, M. Zhou and X. Zhao, J. Mol. Catal. A, 253 (2006).

44. M.D. Hernandez-Alonso, F. Fresno, S. Suarez, J.M. Coronado, Energy Environ. Sci., 2 (2009) 1231-1257.

45. Y-C. Nah, I. Paramasivam, P. Schmuki, Chem. Phys. Chem. 11 (2010) 2698.

46. V. Likodimos, T. Stergiopoulos, P. Falaras, J. Kunze, P. Schmuki, J. Phys. Chem. C, 112 (2008) 12687-12696.

47. A. G. Kontos, A. Katsanaki, T. Maggos, V. Likodimos, A. Ghicov, D. Kim, J. Kunze, C. Vasilakos, P. Schmuki, P. Falaras, Chem. Phys. Lett. 490 (2010) 58.

48. A. G. Kontos, A. I. Kontos, D. S. Tsoukleris, V. Likodimos, J. Kunze, P. Schmuki, P. Falaras, Nanotechnology, 20 (2009) 045603.

49. H. Irie, Y. Watanabe, K. Hashimoto, Chem. Lett., 32 (2003).

50. S. Sakthivel and H. Kisch, Angew. Chem. Int. Ed., 42 (2003).

51. T. Morikawa, R. Asahi, T. Ohwaki, K. Aoki and Y. Taga, Jpn. J. Appl. Phys., 40 (2001).

52. A. Fujishima, X. Zhang, D. A. Tryk, Surface Science Reports 63 (2008) 515-582.

53. A.V. Emeline, V. N. Kuznetsov, V. K. Rybchuk, N. Serpone, International Journal of Photoenergy, (2008) 258394.

54. S. Sato, Chem. Phys. Lett. 123 (1986) 126-128.

55. S. Sato, R. Nakamura, S. Abe, Appl. Catal. A: General 284 (2005) 131-137.

56. R. Asahi, T. Morikawa, T. Ohwaki, K. Aoki, Y. Taga, Science 293 (2001) 269271.

57. N. Serpone, J. Phys. Chem. B 110 (2006) 24287-24293.

58. C. Di Valentin, E. Finazzi, G. Pacchioni, A. Selloni, S. Livraghi, M. C. Paganini, E. Giamello, Chem. Phys. 339 (2007) 44-56.

59. S.U.M. Khan, M. Al-Shahry, W.B. Ingler, Science 297 (2002) 2243-2245. 
60. Y. Izumi, T. Itoi, S. Peng, K. Oka, Y. Shibata, J. Phys. Chem. C 113 (2009) 67066718.

61. J. Zhang, Y. Wu, M. Xing, S.A.K. Leghari, S. Sajjad, Energy Environ. Sci. 3 (2010) 715-726.

62. Y. Nakano, T. Morikawa, T. Ohwaki, Y. Yaga, Appl. Phys. Lett. 86 (2005) 132104.

63. J.M. Mwabora, T. Lindgren, E. Avendano, T.F. Jaramillo, J. Lu, S.E. Lindqusit, C.G. Granqvist, J. Phys. Chem. B 108 (2004) 20193-20198.

64. S-H. Lee, E. Yamasue, H. Okumura, K.N. Ishihara, Appl. Catal. A: General 371 (2009) 179-190.

65. E. Martínez-Ferrero, Y. Sakatani, C. Boissière, D. Grosso, A. Fuertes, J. Fraxedas, C. Sanchez, Adv. Funct. Mater. 17 (2007) 3348-3354.

66. G. Abadias, F. Paumier, D. Eyidi, P. Guerin, T. Girardeau, Surf. Interf. Anal. 42 (2010) 970-973.

67. J. Premkumar, Chem. Mater. 16 (2006) 3980-3981.

68. Li Jinlong, M. Xinxin, S. Mingren, X. Li, S. Zhenlun, Thin Solid Films 519 (2010) 101-105.

69. A. Kafizas, C. Crick, I. P. Parkin, J. Photochem. Photobiol. A: Chem. 216 (2010) 156-166.

70. C.W.H. Dunnill, Z. A. Aiken, J. Pratten, M. Wilson, D. J. Morgan, I. P. Parkin, J. Photochem. Photob. A: Chem. 207 (2009) 244-253.

71. C. Sarantopoulos, A. N. Gleizes, F. Maury, Thin Solid Films 518 (2009) 12991303.

72. V. Pore, M. Heikkilä, M. Ritala, M. Leskelä, S. Arev, J. Photochem. Photob. A: Chem. 177 (2006) 68-75.

73. L. Zhao, Q. Jiang, J. Lian, Appl. Surf. Sci., 254 (2008) 4620-4625.

74. D. Mitoraj, H. Kisch, Chem. Eur. J. 16 (2010) 261-269.

75. T.C. Jagadale, S. P. Takale, R.S. Sonawane, H.M. Joshi, S.I. Patil, B. Kale, S. B. Ogale, J. Phys. Chem. C 112 (2008) 14595-14602.

76. X. Qiu, Y. Zhao, C. Burda, Adv. Mater. 19 (2007) 3995-3999.

77. T. Sano, N. Negishi, K. Koike, K. Takeuchi, S. Matsuzawa, J. Mater. Chem. 14 (2004) 380-384.

78. C. Belver, R. Bellod, A. Fuerte, M. Fernandez-Garcia, Appl. Catal. B: Environ. 65 (2006) 301-308.

79. A. I. Kontos, A. G. Kontos, Y. S. Raptis, P. Falaras, Phys. Stat. Sol. (RRL) 2 (2008) 83-85.

80. H. Choi, M. G. Antoniou, M. Pelaez, A. A. de la Cruz, J. A. Shoemaker, D. D. Dionysiou, Environ. Sci. Technol. 41 (2007) 7530-7535.

81. H. Choi, A. C. Sofranko, D. D. Dionysiou, Adv. Funct. Mater. 16 (2006) 10671074.

82. H. Choi, E. Stathatos, D. D. Dionysiou, Appl. Catal. B 63 (2006) 60-67.

83. X. Fang, Z. Zhang, Q. Chen, H. Ji, X. G. Journal of Solid State Chemistry 180 (2007) 1325-1332.

84. F.E. Oropeza, J. Harmer, R. G. Egdell, R. G. Palgrave, Phys. Chem. Chem. Phys. 12 (2010) 960-969. 
85. Y. Irokawa, T. Morikawa, K. Aoki, S. Kosaka,T. Ohwaki,Y. Taga, Phys. Chem. Chem. Phys. 8 (2006) 1116-1121.

86. D.J.V. Pulsipher, I. T. Martin, E.R. Fisher, Appl. Mat. Interf. 2 (2010) 1743-1753.

87. V. Etacheri, M. K. Seery, S. J. Hinder, S. C. Pillai, Chem. Mater. 22 (2010) 38433853.

88. Q. Li, J. K. Shang, J. Am. Ceram. Soc. 91 (2008) 3167-3172.

89. J. Wang, De N. Tafen, J. P. Lewis, Z. Hong, A. Manivannan, M. Zhi, M. Li, N. Wu, J. Am. Chem. Soc. 131 (2009) 12290-12297.

90. R.P. Vitiello, J. M. Macak, A. Ghicov, H. Tsuchiya, L. F. P. Dick, P. Schmuki, Electrochem. Commun. 8 (2006) 544-548.

91. A. Ghicov, J-M. Macak, H. Tsuchiya, J. Kunze, V. Haeublein, L. Frey, P. Schmuki, Nano Lett. 6 (2006) 1080-1082.

92. K.S. Han, J.W. Lee, Y.M. Kang, J.Y. Lee, J.K. Kang, Small 4 (2008) 1682-1686.

93. J. Wang, Z. Wang, H. Li, Y. Cui, Y. Du, J. Alloys Comp. 494 (2010) 372-377.

94. C. Liu, H. Sun, S. Yang, Chem. Eur. J. 16 (2010) 4381-4393.

95. K. Shankar, K. C. Tep, G.K. Mor, C.G. Grimes, J. Phys. D: Appl. Phys. 39 (2006) 2361-2366.

96. D. Wu, M. Long, W. Caia C. Chen, Y. Wu, J. Alloys Comp. 502 (2010) 289-294.

97. G. Liu, L. Wang, C. Sun, Z. Chen, X. Yan, L. Cheng, H-M. Cheng, G.Q. Lu, Chem. Commun. (2009) 1383-1385.

98. X. Chen, Y. Lou, A. C. S. Samia, C. Burda, J. L. Cole, Adv. Funct. Mater. 15 (2005) 41-49.

99. M. Batzill, E.H. Morales, U. Diebold, Phys. Rev. Lett., 96 (2006) 026103-4.

100. P. Romero-Gomez, V. Rico, A. Borras, A. Barranco, J.P. Espinos. J. Cotrino, A.R. Gonzalez-Elipe, J. Phys. Chem. C 113 (2009) 13341-13351.

101. A. Braun, K. K. Akurati, G. Fortunato, F. A. Reifler, A. Ritter, A.S. Harvey, A. Vital, T. Graule, J. Phys. Chem. C 114 (2010) 516-519.

102. K. Hashimoto, H. Irie, A. Fujishima. Japan. J. Appl. Phys. 44 (2005) 8269-8285.

103. R. Katoh, A. Furube, K-i Yamanaka, T. Morikawa, J. Phys. Chem. Lett. 1 (2010) 3261-3265.

104. A.M. Czoska, S. Livraghi, M. Chiesa, E. Giamello, S. Agnoli, G. Granozzi, E. Finazzi, C. Di Valentin, G. Pacchioni, J. Phys. Chem. C, 112 (2008) 8951-8956.

105. Sibu C. Padmanabhan, Suresh C. Pillai, John Colreavy, Sivakumar Balakrishnan, Declan E. McCormack, Tatiana S. Perova, Yurii Gunko, Steven J. Hinder, John M. Kelly, Chem. Mater., 19 (2007) 4474-4481.

106. K. Nagaveni, M. S. Hedge, N. Ravishankar, G. N. Subbanna, G. Madras, Langmuir, 20 (2004) 2900-2907.

107. T. Umebayashi, T. Yamaki, H. Itoh, K. Asai, Appl. Phys. Lett., 81 (2002) 454.

108. D. B. Hamal, K. J. Klabunde, J. Colloid Interface Sci., 311 (2007) 514-522.

109. Pradeepan Periyat, Declan E. McCormack, Steven J. Hinder, Suresh C. Pillai, J. Phys. Chem. C, 113 (2009) 3246-3253.

110. Pradeepan Periyat, Suresh C. Pillai, Declan E. McCormack, John Colreavy, Steven J. Hinder, J. Phys. Chem. C 112 (2008) 7644-7652.

111. C. Han, M. Pelaez, V. Likodimos, A.G. Kontos, P. Falaras, K. O'Shea, D.D. Dionysiou, Appl. Catal. B: Environ., 107 (2011) 77-87.

112. Y. Xie, Y. Li, X. Zhao, J. Mol. Catal. A: Chem., 277 (2007) 119-126. 
113. S. Liu, J. Yu, W. Wang, Phys. Chem. Chem. Phys., 12 (2010) 12308-12315.

114. G. Wu, J. Wen, S. Nigro, A. Chen, Nanotechnology 21 (2010) 085701.

115. C. Di Valentin, E. Finazzi, G. Pacchioni, A. Selloni, S. Livraghi, A. M. Czoska, M. C. Paganini, E. Giamello, Chem. Mater., 20 (2008) 3706-3714.

116. M. Pelaez, A. A. de la Cruz, E. Stathatos, P. Falaras, D. D. Dionysiou, Catalysis Today, 2009, 144, 19-25.

117. M. Pelaez, P. Falaras, V. Likodimos, A.G. Kontos, A. A. De la Cruz, K. O’ Shea, D. D. Dionysiou, Appl. Catal. B: Envir., 99 (2010) 378-387.

118. J. Xu, B. Yang, M. Wu, Z. Fu, Y. Lv, Y. Zhao J. Phys. Chem. C 114 (2010) 15251-15259.

119. V. Etacheri, M. K. Seery, S. J. Hinder,S. C. Pillai, Adv. Funct. Mater. 21 (2011) 3744-3752.

120. E. Borgarello, J. Kiwi, M. Gratzel, E. Pelizzetti, M. Visca, J. Am. Chem. Soc., 104 (1982) 2996-3002.

121. M. Iwasaki, M. Hara, H. Kawada, H. Tada, S. Ito, J. Colloid Interface Sci., 224 (2000) 202-204.

122. S. Klosek, D. Raftery, J. Phys. Chem. B 105 (2001) 2815-2819.

123. J. Zhu, F. Chen, J. Zhang, H. Chen, M. Anpo, J. Photochem. Photobiol. A, 180 (2006) 196-204.

124. M. Kang, Mat. Lett., 59 (2005) 3122-3127.

125. T. Morikawa, Y. Irokawa, T. Ohwaki, Appl. Catal. A Gen., 314 (2006) 123-127.

126. X. Z. Li and F. B. Li, Environ. Sci. Technol., 35 (2001) 2381-2387.

127. K. Demeestre, J. Dewulf, T. Ohno, P. H. Salgado, H. V. Langenhove, Appl. Catal. B: Environ., 61 (2005) 140-149.

128. D. Dvoranova, V. Brezova, M. Mazur and M. A. Malati, Appl. Catal. B: Environ., 37 (2002) 91-105.

129. A. Fuerte, M. D. Hernandez-Alonso, A. J. Maira, A. Martinez-Arias, M.

Fernandez-Garcia, J. C. Conesa and J. Soria, Chem. Commun., 2001, 2718-2719.

130. K. Iketani, R.-D. Sun, M. Toki, K. Hirota, O. Yamaguchi, Mater. Sci. Eng. B, 108 (2004) 187-193.

131. F. B. Li and X. Z. Li, Chemosphere 48 (2002) 1103-1111.

132. T. Ohno, F. Tanigawa, K. Fujihara, S. Izumi, M. Matsumara, J. Photochem. Photobiol. A, 127 (1999) 107-110.

133. J. C.-S. Wu and C.-H. Chen, J. Photochem. Photobiol. A, 293 (2004) 509-515.

134. H. Yamashita, M. Harada, J. Misaka, M. Takeuchi, K. Ikeue, M. Anpo, J.

Photochem. Photobiol. A, 148 (2002) 257-261.

135. H. Yamashita, M. Harada, J. Misaka, M. Takeuchi, B. Neppolian, M. Anpo, Catal. Today, 84 (2003) 191-196.

136. D. Behar and J. Rabani, J. Phys. Chem. B 110 (2006) 8750-8755.

137. S. K. Kim, S. J. Hwang, W. Choi, Environ. Sci. Technol., 35 (2001) 2381-2387.

138. Y. Zeng, W. Wu, S. Lee, J. Gao, Catal. Commun. 8 (6) (2007) 906-912.

139. W. Wang, J. Zhang, F. Chen, D. He and M. Anpo, J. Colloid Interface Sci., 323 (2008) 182-186.

140. X. You, F. Chen, J. Zhang, M. Anpo, Catal. Lett., 102 (2005) 247-250.

141. M. K. Seery, R. George, P. Floris, S. C. Pillai, J. Photochem. Photobiol. A, 189 (2007) 258-263. 
142. Gunawan, C., Teoh, W. Y., Marquis, C. P., Lifia, J., Amal, R., Small 5 (2009) 341-344.

143. N. T. Nolan, M. K. Seery, S. J. Hinder, L. F. Healy, S. C. Pillai J. Phys. Chem. C 114 (2010) 13026-13034.

144. T. Wu, T. Lin, J. Zhao, H. Hidaka, N. Serpone, Environ. Sci. Technol. 33 (1999) 1379.

145. T. Wu, G. Liu, J. Zhao, H. Hidaka, N. Serpone, J. Phys. Chem. B 102 (1998) 5845.

146. Y. Cho, W. Choi, C.H. Lee, T. Hyeon, H.I. Lee, Environ. Sci. Technol. 35966 (2001).

147. Y. Xu, C.H. Langford, Langmuir 17 (2001) 897.

148. D. Chatterjee, S. Dasgupta, N.N. Rao, Sol. Energy Mater. Sol. Cells, 90 (2006) 1013.

149. K. Vinodgopal, U. Stafford, K.A. Gray, P.V. Kamat, J. Phys. Chem. 98 (1994) 6797.

150. K. Vinodgopal, I. Bedja, P.V. Kamat, Chem. Mater. 8 (1996) 2180.

151. A. J. Nozik, R. Memming, J. Phys. Chem. 100 (1996) 13061.

152. J. B. Asbury, E. Hao, Y. Wang, H.N. Ghosh, T. Lian, J. Phys. Chem. B, 105 (2001) 4545.

153. P.V. Kamat, Prog. React. Kinet. 19 (1994) 277.

154. A. Hagfeldt, M. Gratzel, Chem. Rev. 95 (1995) 49.

155. G. Marci, V. Augugliaro, M. J. López-Muñoz, C. Martin, L. Palmisano, V. Rives, M. Schiavello, R. J. D. Tilley, A. M. Venezia, J. Phys. Chem. B 105 (2001) 1026.

156. N. Ghows, M.H. Entezari, Ultrason. Sonochem., 18 (2011) 629.

157. R. Brahimi, Y. Bessekhouad, A. Bouguelia, M. Trari, Catal. Today 122 (2007) 62.

158. P.V. Kamat, J. Phys. Chem. C 112 (2008) 18737.

159. S.J. Jum, G.K. Hyun, A.J. Upendra, W.J. Ji, S.L. Jae, Int. J. Hydrogen Energy, 33 (2008) 5975.

160. K.S. Leshkies, R. Duvakar, J. Basu, E.E. Pommer, J.E. Boercker, C.B. Carter, U.R. Kortshagen, D. J. Norris, E. S. Aydil, Nano Lett. 7 (2007) 1793.

161. J.S. Jang, S.M. Ji, S.W. Bae, H.C. Son, J.S. Lee, J. Photochem. Photobiol. A: Chem., 188 (2007) 112.

162. D. Robert, Catalysis Today, 122 (2007) 20.

163. Y. Bessekhouad, D. Robert, J.-V. Weber, Catalysis Today, 101 (2005) 315.

164. S. Li, Y.-H. Lin, B.-P. Zhang, J.-F. Li,C.-W. Nan, J. Appl. Phys., 105 (2009) 054310.

165. Li, Y. Hou, Q. Zhao, G. Chen, Langmuir 27 (2011) 3113-3120.

166. I. Robel, V. Subramanian, M. Kuno, P.V. Kamat, J. Am. Chem. Soc., 128 (2006) 2385.

167. A. Kongkanand, K. Tvrdy, K. Takechi, M. Kuno, P.V. Kamat, J. Am. Chem. Soc., 130 (2008) 4007.

168. T. Trindade, P. O’Brien, N.L. Pickett, Chem. Mater., 13 (2001) 3843.

169. C. Wang, H. Zhang, J. Zhang, M. Li, H. Sun, B. Yang, J. Phys. Chem. C 111 (2007) 2465. 
170. K. Tvrdy, P.V. Kamat, J. Phys. Chem. A 113 (2009) 3765.

171. M. Shalom, S. Dor, S. Rühle, L. Grinis, A. Zaban, J. Phys. Chem. C 113 (2009) 3895.

172. R. Vogel, P. Hoyer, H. Weller, J. Phys. Chem., 98 (1994) 3183.

173. L. Spanhel, H. Weller, A. Henglein , J. Am. Chem. Soc., 109 (1987) 6632.

174. Y. Bessekhouad, N. Chaoui, M. Trzpit, N. Ghazzal, D. Robert, J. V. Weber, J. Photochem. Photobiol. A: Chem., 183 (2006) 218.

175. N. Serpone, P. Marathamuthu, P. Pichat, E. Pelizzetti, H. Hidaka, J. Photochem. Photobiology, 85 (1995) 247.

176. J. Wang, K.P. Loh, Y.L. Zhong, M. Lin, J. Ding, Y.L. Foo, Chem. Mater., 19 (2007) 2566.

177. M. Ammar, F. Mazaleyrat, J.P. Bonnet, P. Audebert, A. Brosseau, G. Wang, Y. Champion, Nanotechnology 18 (2007) 285606.

178. S.S. Lee, K.W. Seo, S.H. Yoon, I.-W. Shim, K.-T. Byun, H.-Y. Kwak, Bull. Korean Chem. Soc., 26 (2005) 1579.

179. K.-T. Byun, K.W. Seo, I.-W. Shim, H.-Y. Kwak, Chem. Eng. J., 135 (2008) 168. 180. X. Chen, L. Liu, P. Y. Yu, S. S. Mao, Science 331 (2011) 746-750.

181. M. Stylidi, D.I. Kondarides, X.E. Verykios, Appl. Catal. B: Environ., 47 (2004) 189.

182. C. Schweitzer, R. Schmidt, Chem. Rev., 103 (2003) 1685.

183. E. Frati, A.-M. Khatib, P. Front, A. Panasyuk, F. Aprile, D.R. Mitrovic, Free Radic. Biol. Med., 22 (1997) 1139.

184. J. Bandara, J. Kiwi, New J. Chem., 23 (1999) 717.

185. D. Chatterjee, A. Mahata, Catal. Commun., 2 (2001) 1.

186. D. Zhang, R. Qiu, L. Song, B. Eric, Y. Mo, X. Huang, J. Hazard. Mater., 163 (2009) 843.

187. Y. Lion, M. Delmelle, A. Van de Vorst, Nature 263 (1976) 442.

188. G.M. Liu, X.Z. Li, J.C. Zhao, S. Horikoshi, H. Hidaka, J. Mol. Catal. A, 153 (2000) 221.

189. C.C. Chen,W.H. Ma, J.C. Zhao, J. Phys. Chem. B 106 (2002) 318.

190. W. Zhao, C.C. Chen, X.Z. Li, J.C. Zhao, J. Phys. Chem. B 106 (2002) 5022.

191. H. Park,W. Choi, J. Phys. Chem. B 108 (2004) 4086.

192. Y.X. Chen, S.Y. Yang, K. Wang, L.P. Lou, J.Photochem. Photobiol. A, 172 (2005) 47.

193. J.W. J. Hamilton, J. A. Byrne, P. S. M. Dunlop, N. M. D. Brown, International Journal of Photoenergy (2008) Article ID 185479.

194. J.W. J. Hamilton, J. A. Byrne, C. McCullagh, and P. S. M. Dunlop, International Journal of Photoenergy (2008) Article ID 631597.

195. R. Nakamura, T. Tanaka, Y. Nakato, J. Phys. Chem. B 108 (2004) 10617-10620.

196. R. Beranek and H. Kisch, Electrochemistry Communications 9 (2007) 761-766.

197. A.V. Emeline, X. Zhang, M. Jin, T. Murakami, A. Fujishima, J. Photochem.

Photobiol. A: Chem., 207 (2009) 13-19.

198. J. Senthilnatan and Ligy Philip, Chemical Engineering Journal 161 (2010) 8392.

199. D. V. Sojic, V. N. Despotovic, N. D. Abazovic, M. I. Comor, B. F. Abramovic. J. Hazard. Mater. 179 (2010) 49-56. 
200. M. M. Mohamed, K. S. Khairou, Microporous and Mesoporous Materials 142 (2011) 130-138.

201. X. Wang, T-T. Lim, Applied Catalysis B: Environ. 100 (2010) 355-364.

202. D. P. Subagio, M. Srinivasan, M. Lim, T-T. Lim, Appl. Catal. B: Environ. 95 (2010) 414-422.

203. P-S. Yap, T-T. Lim, M. Lim, M. Srinivasan, Catal. Today 151 (2010) 8-13.

204. D. Graham, H. Kisch, L. A. Lawton, P. K. J. Robertson, Chemosphere 78 (2010) 1182-1185.

205. D. Li, Z. Chen, Y. Chen, W. Li, H. Huang, Y. He, X. Fu, Environ. Sci. Technol. 2008, 42, 2130-2135.

206. Z. Wei, J. Sun, Z. Xie, M. Liang, S. Chen. Journal of Hazardous Materials, 177 (2010) 814-821.

207. S. Malato, P. Fernandez-Ibanez, M. I. Maldonado, J. Blanco, W. Gernjak, Catal. Today, 147 (2009) 1-59.

208. T. Matsunaga, R. Tomoda, T. Nakajima, H. Wake, FEMS Micro. Lett., 29 (1985) 211-214.

209. J. C. Yu, W. Ho, J. Yu, H. Yip, P. K. Wong, J. Zhao, Environ. Sci. Technol., 39 (2005) 1175-1179.

210. Y. Liu, J. Li, X. Qiu, C. Burda, Wat. Sci. Technol., 54 (2006) 47-54.

211. Q. Li, R. Xie, Y. W. Li, E. A. Mintz, J. K. Shang, Environ. Sci. Technol., 41 (2007) 5050-5056.

212. D. Mitoraj, A. Janczyk, M. Strus, H. Kisch, G. Stochel, P. B. Heczko, W. Macyk, Photochem. Photobiol. Sci., 6 (2007) 642-648.

213. C. W. Dunnill, Z. A. Aiken, A. Kafizas, J. Pratten, M. Wilson, D. J. Morgan, I. P. Parkin, J. Mat. Chem., 19 (2009) 8747-8754.

214. Q. Li, M. A. Page, B. J. Mariñas, J. K. Shang, Environ. Sci. Technol., 42 (2008) 6148-6153.

215. P. Wu, R. Xie, K. Imlay, J. K. Shang, Environ. Sci. Technol., 44 (2010) 69926997.

216. S. Swetha, S. M. Santhosh, R. G. Balakrishna, Photochem. \& Photobiol., 86 (2010) 1127-1134.

217. J. A. Rengifo-Herrera, E. Mielczarski, J. Mielczarski, N. C. Castillo, J. Kiwi, C, Pulgarin, Appl. Catal. B: Environ., 84 (2008) 448-456.

218. J. A. Rengifo-Herrera, C. Pulgarin, J. Photochem. Photobiol., A, 205 (2009) 109-115.

219. J. A. Rengifo-Herrera, K. Pierzchala, A. Sienkiewicz, L. Forro, J. Kiwi, C. Pulgarin, Appl. Catal. B-Environ., 88 (2009) 398-406.

220. J. A. Rengifo-Herrera, K. Pierzchała, A. Sienkiewicz, L. Forr, J. Kiwi, J. E. Moser, C. Pulgarin, J. Phys. Chem. C 114 (2010) 2717-2723.

221. J. A. Rengifo-Herrera, C. Pulgarin, Sol. Energy, 84 (2010) 37-43.

222. N. Serpone, G. Sauve, R. Koch, H. Tahiri, P. Pichat, P. Piccinini, E. Pelizzetti, H. Hidaka, J., Photochem. Photobiol. A: Chem., 94 (1996) 191-203. 223. N. Serpone, R. Terzian, D. Lawless, P. Kennepohl, G. Sauve, J. Photochem. Photobiol. A: Chem., 73 (1993) 11-16. 224. R.W. Matthews, S.R. McEvoy, J. Photochem. Photobiol. A: Chem., 66 (1992) 355-366. 
225. A. Mills, S. Morris, J. Photochem. Photobiol. A: Chem., 71 (1993) 75-83.

226. J.R. Bolton, R.G. Bircher, W. Tumas, C.A. Tolman, J. Adv. Oxid.Technol. 1 (1996) 13-17.

227. J. Ryu, W. Choi, Environ. Sci. Technol. 42 (2008) 294-300.

228. J.M. Herrmann, Appl. Catal. B: Environ., 99 (2010) 461-468.

229. M. Vautier, C. Guillard, J.M. Herrmann, J. Catal., 201 (2001) 46-59.

230. International Standards Organization, Fine ceramics (advanced ceramics, advanced technical ceramics) -- Determination of photocatalytic activity of surfaces in aqueous medium by degradation of methylene blue. ISO/CD10678.

231. X. Yan, T. Ohno, K. Nishijima, R. Abe, B. Ohtani, Chem. Phys. Lett., 429 (2006) 606-610.

232. P.S.M. Dunlop, A. Galdi, T.A. McMurray, J.W.J. Hamilton, L. Rizzo, J.A. Byrne, J. Adv.Oxid.Technol., 13 (2010) 99-106.

233. T.A. McMurray, J.A. Byrne, P.S.M. Dunlop, J.G.M. Winkelman, B.R. Eggins, B.R., E.T. McAdams, E.T., Appl. Catal. A: Gen., 262 (2004) 105-110.

234. L. Zhang and J. C. Yu, Catal. Comm., 6 (2005) 684-687.

235. L. X. Cao, Z. Cao, S. L. Suib, T. N. Obee, S. O. Hay, J. D. Freihauty, J. Catal., 196 (2000) 253.

236. E. Piera, J. A. Ayllon, X. Domenach, J. Peral, Catal. Today, 76 (2002) 259-270.

237. J. Peral and D. F. Ollis, Photocatalytic Purification and Treatment of Water and Air, Elsevier, New York, 1993.

238. U. R. Pillai and E. Sahle-Demessie, J. Catal., 211 (2002) 434-444.

239. J. Shang, Y. F. Zhu, Y. G. Du and Z. L. Xu, J. Sol. State Chem., 166 (2002) 395399.

240. M. M. Ameen and G. B. Raupp, J. Catal., 184 (1999) 112-122. 


\section{Figure Captions}

Figure 1. Crystalline structures of titanium dioxide (a) rutile, (b) anatase, (c) brookite (Reprinted with permission from Katsuhiro Nomura (nomura-k@aist.go.jp; http://staff.aist.go.jp/nomura-k/english/itscgallary-e.htm) Copyright (2002)).

Figure 2. Schematic of $\mathrm{TiO}_{2}$ photocatalytic mechanism.

Figure 3. Templating sol-gel method utilizing nitrogen containing surfactants as both nitrogen source and pore template material. (Reprinted with permission from H. Choi, M. G. Antoniou, M. Pelaez, A. A. de la Cruz, J. A. Shoemaker, D. D. Dionysiou, Environ. Sci. Technol. 41 (2007) 7530-7535. Copyright (2007) American Chemical Society).

Figure 4. Electron transfer mechanism in $\mathrm{N}$-doped anatase rutile heterojunction. (Reprinted with permission from V. Etacheri, M. K. Seery, S. J. Hinder, S. C. Pillai, Chem. Mater. 22 (2010) 3843-3853. Copyright (2010) American Chemical Society).

Figure 5. Mechanism of band gap narrowing by oxygen excess. Number 2 and 16 in $\mathrm{H}_{2} \mathrm{O}_{2}-\mathrm{TiO}_{2}$ was used to identified two different modified titania samples. (Reprinted with permission from V. Etacheri , M. K. Seery, S. J. Hinder ,S. C. Pillai, Adv. Funct. Mater. 21 (2011) 3744-3752. Copyright (2011) Wiley VCH).

Figure 6. Mechanism for light absorption of silver supported in $\mathrm{TiO}_{2}$. (Adapted with permission from N. T. Nolan, M. K. Seery, S. J. Hinder, L. F. Healy, S. C. Pillai J. Phys. Chem. C 114 (2010), 13026-13034. Copyright (2010) American Chemical Society).

Figure 7. TEM and mechanistic image of the interface between $\mathrm{CdS}$ nanowires and $\mathrm{TiO}_{2}$ nanoparticles. $\mathrm{TiO}_{2}$ provide sites for collecting the photoelectrons generated from $\mathrm{CdS}$ nanowires, enabling thereby an efficient electron-hole separation. (Reprinted with permission from S.J. Jum, G.K. Hyun, A.J. Upendra, W.J. Ji, S.L. Jae, Int. J. Hydrogen Energy, 33 (2008) 5975. Copyright (2008) Elsevier).

Figure 8. The UV-vis absorbance spectra of pure and composite semiconductors. (Reprinted with permission from N. Ghows, M.H. Entezari, Ultrason. Sonochem., 18 (2011) 629. Copyright (2008) Elsevier).

Figure 9. Proposed mechanism that shows the interaction of one species from the core with one species from the shell for the removal of RB5 by nanocomposite $\mathrm{CdS} / \mathrm{TiO}_{2}$. (Reprinted with permission from N. Ghows, M.H. Entezari, Journal of Hazardous Materials, 195 (2011) 132. Copyright (2011) Elsevier).

Figure 10. \%IPCE as a function of wavelength for the photooxidation of water on $\mathrm{TiO}_{2}$ (red) and $\mathrm{WO}_{3}$ (blue) (Adapted with permission from J.W. J. Hamilton, J. A. Byrne, P. S. M. Dunlop, N. M. D. Brown, International Journal of Photoenergy (2008) Article ID 185479. Copyright (2008) Hindawi Publishing Corporation). 
1 Figure 11. Effect of the addition of $0.5 \mathrm{mM} \mathrm{I}^{-}, \mathrm{H}_{2} \mathrm{Q}, \mathrm{SCN}^{-}$, and $\mathrm{Br}^{-}$on IPCE vs $\lambda$ in the 2 (a) $\mathrm{UV}$ - and (b) visible-light regions for $\mathrm{N}$-doped $\mathrm{TiO}_{2}$. The supporting electrolyte was $30.1 \mathrm{M} \mathrm{HClO}_{4}$ and the electrode potential was $0.5 \mathrm{~V}$ vs $\mathrm{Ag} / \mathrm{AgCl}$ (Reprinted with 4 permission from R. Nakamura, T. Tanaka, Y. Nakato, J. Phys. Chem. B 108 (2004) 5 10617-10620. Copyright (2004) American Chemical Society).

Figure 12. Energy levels for $\mathrm{N}$-doped $\mathrm{TiO}_{2}$ (anatase) relative to reported equilibrium redox potentials for one-electron-transfer redox couples (Reprinted with permission from R. Nakamura, T. Tanaka, Y. Nakato, J. Phys. Chem. B 108 (2004) 10617-10620. Copyright (2004) American Chemical Society).

Figure 13. IPCE spectra (a) and (IPCE hv) ${ }^{1 / 2}$ vs hv plots (b) for $\mathrm{TiO}_{2}$ and $\mathrm{TiO}_{2}-\mathrm{N}$ recorded in $\mathrm{LiClO}_{4}(0.1 \mathrm{M})+\mathrm{KI}(0.1 \mathrm{M})$ (Reprinted with permission from R. Beranek and H. Kisch, Electrochemistry Communications 9 (2007) 761-766. Copyright (2007) 15 Elsevier).

Figure 14. Proposed bacterial disinfection mechanism during solar excitation of N, S codoped $\mathrm{TiO}_{2}$. (Adapted with permission from J. A. Rengifo-Herrera, C. Pulgarin, Sol. Energy, 84 (2010) 37-43. Copyright (2010) Elsevier).

\section{Table Captions}

Table 1. Physical and structural properties of anatase and rutile $\mathrm{TiO}_{2}$.

26 Table 2. Oxidation potentials of various oxidants relative to NHE. 
Table 1.

\begin{tabular}{lll}
\hline Property & Anatase & Rutile \\
\hline Molecular Weight $(\mathrm{g} / \mathrm{mol})$ & 79.88 & 79.88 \\
Melting point $\left({ }^{\circ} \mathrm{C}\right)$ & 1825 & 1825 \\
Boiling Point $\left({ }^{\circ} \mathrm{C}\right)$ & $2500 \sim 3000$ & $2500 \sim 3000$ \\
Light absorption $(\mathrm{nm})$ & $<390$ & $<415$ \\
Mohr's Hardness & 5.5 & $6.5-7.0$ \\
Refractive index & 2.55 & 2.75 \\
Dielectric constant & 31 & 114 \\
Crystal structure & Tetragonal & Tetragonal \\
Lattice constants $(\AA)$ & $\mathrm{a}=3.78$ & $\mathrm{a}=4.59$ \\
Density $\left(\mathrm{g} / \mathrm{cm}^{3}\right)$ & $\mathrm{c}=9.52$ & $\mathrm{c}=2.96$ \\
Ti-O bond length $(\AA)$ & 3.79 & 4.13 \\
& $1.94(4)$ & $1.95(4)$ \\
\hline
\end{tabular}


Table 2.

\begin{tabular}{cc}
\hline Oxidant & Oxidation Potential $(\mathbf{V})$ \\
\hline$\cdot \mathrm{OH}$ (hydroxyl radical) & 2.80 \\
$\mathrm{O}_{3}$ (Ozone) & 2.07 \\
$\mathrm{H}_{2} \mathrm{O}_{2}$ (hydrogen peroxide) & 1.77 \\
$\mathrm{HClO}_{\text {(hypochlorous acid) }}$ & 1.49 \\
Cl $^{-}$(chlorine) & 1.36 \\
\hline
\end{tabular}




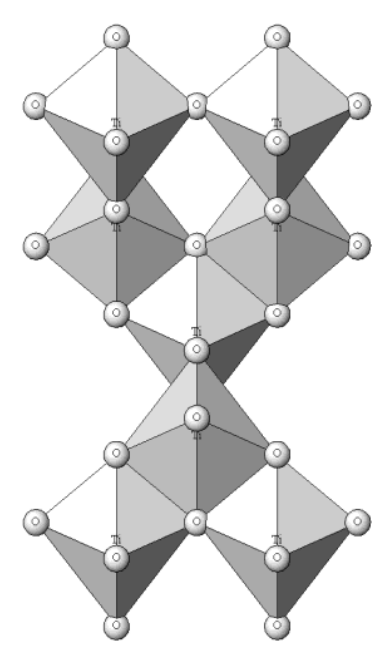

(a)

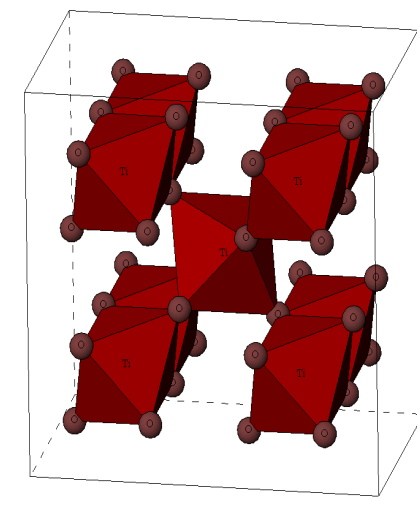

(b)

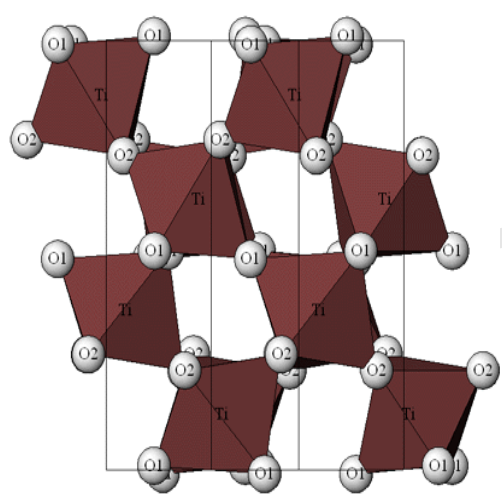

(c)

Figure 1.

Page 39 of 54 


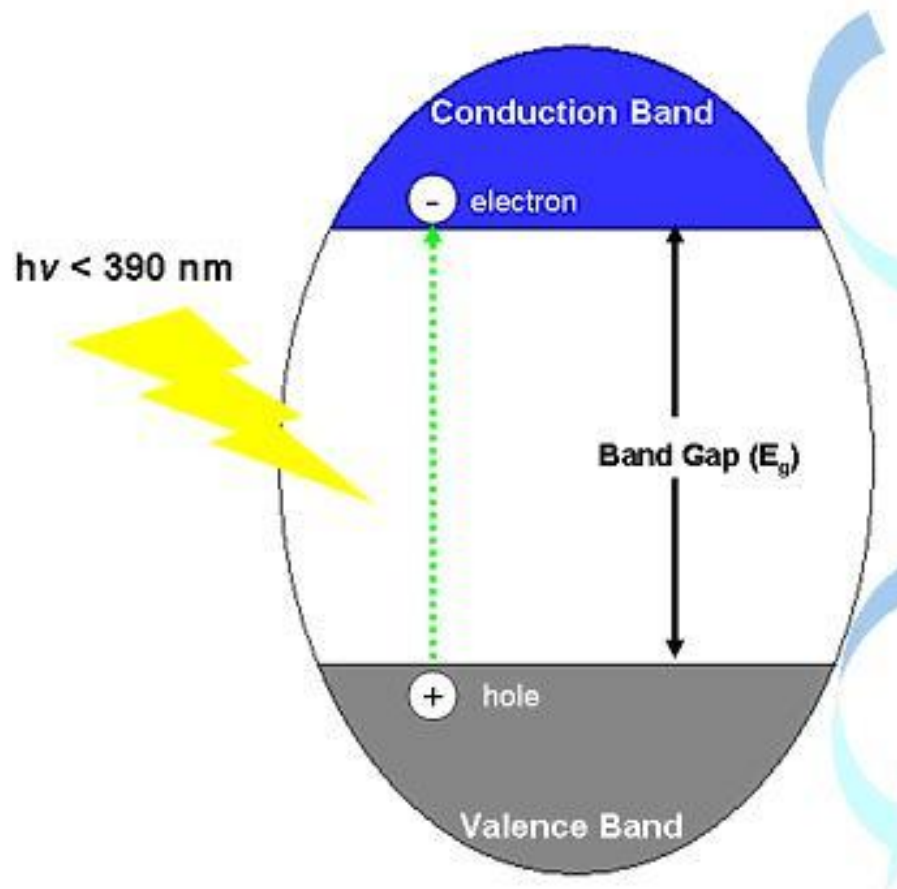

Reduction:

$\mathrm{O}_{2}+\mathrm{e}^{*} \rightarrow \mathrm{O}_{2}^{*-}$

Superoxide

radical

Oxidation:

$\mathrm{H}_{2} \mathrm{O}+\mathrm{h}^{+} \rightarrow \mathrm{OH} \bullet$

Hydroxyl radical

Figure 2. 


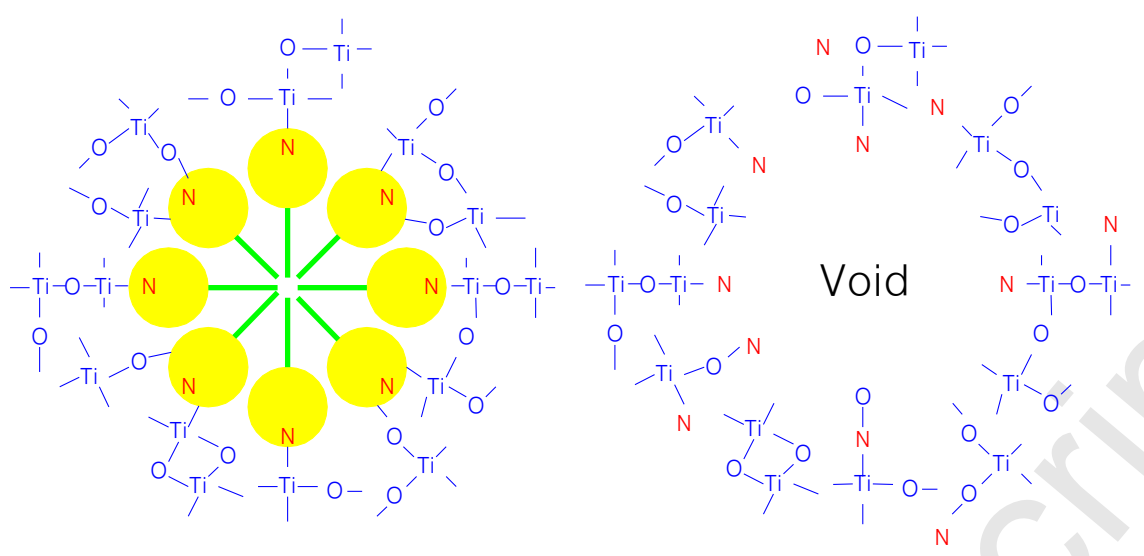

Figure 3. 


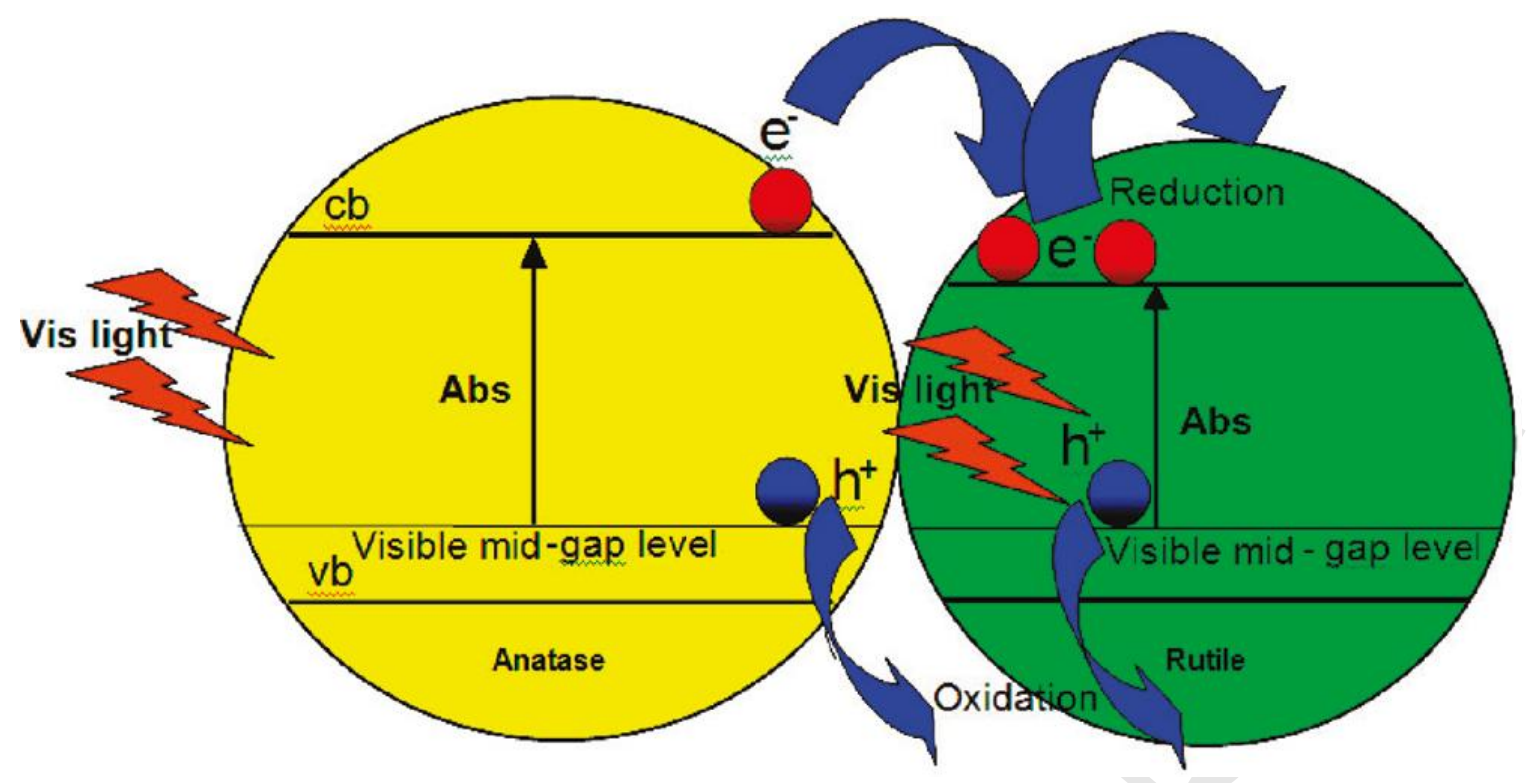

Figure 4. 


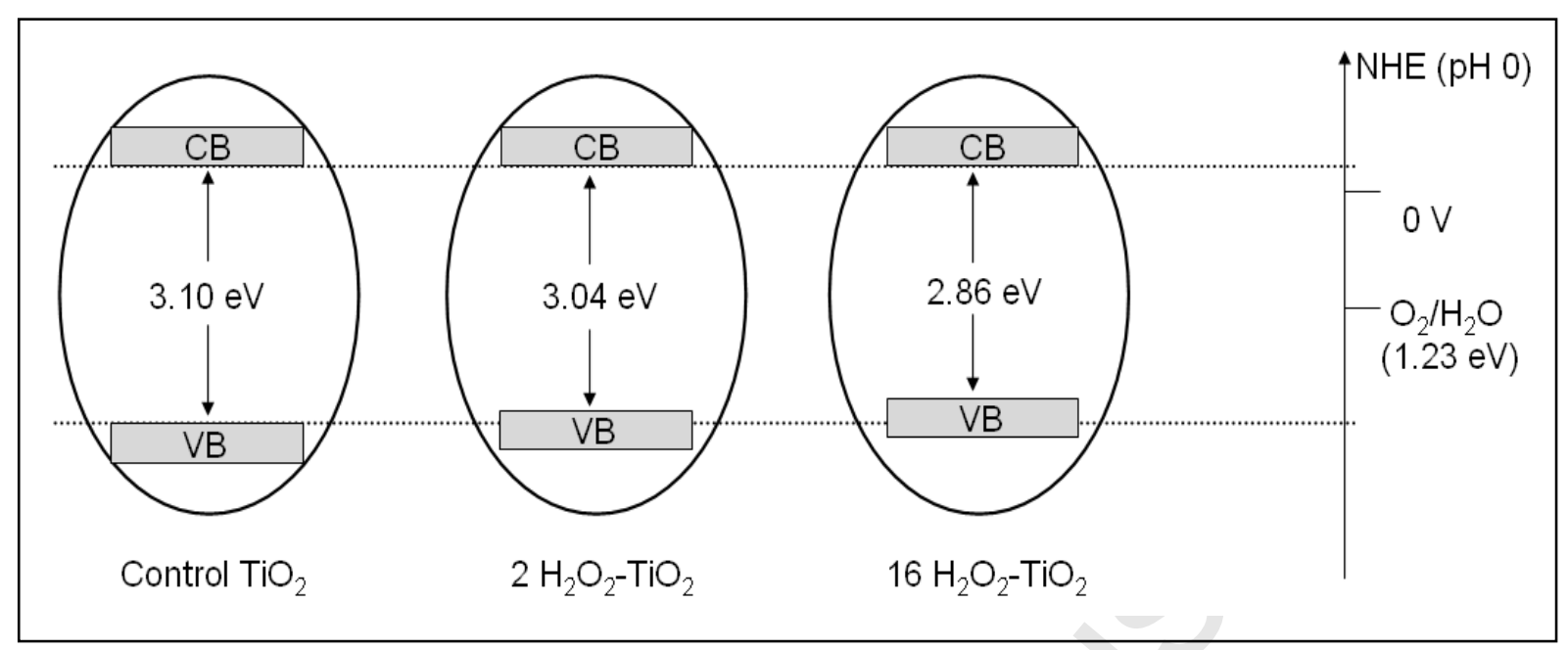

Figure 5. 


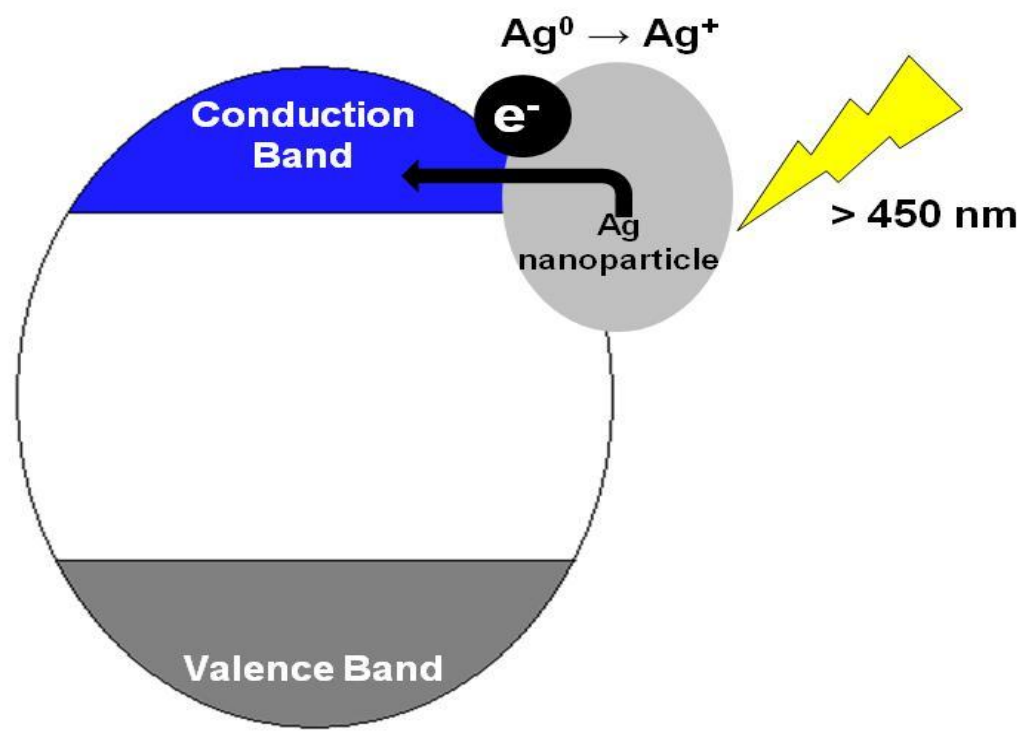

Figure 6. 


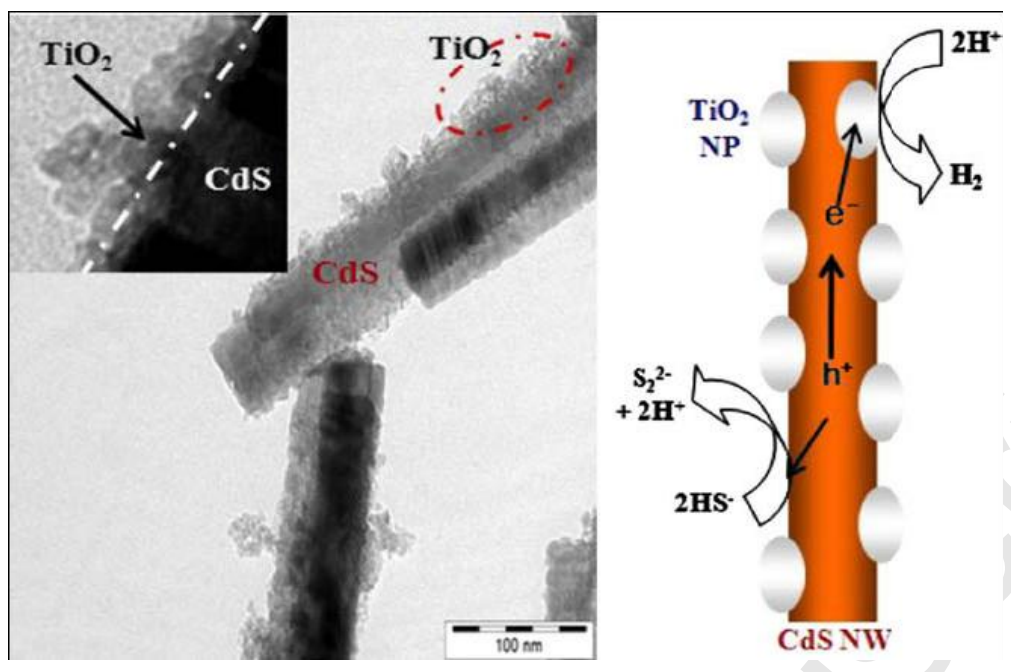

Figure 7.

Page 45 of 54 


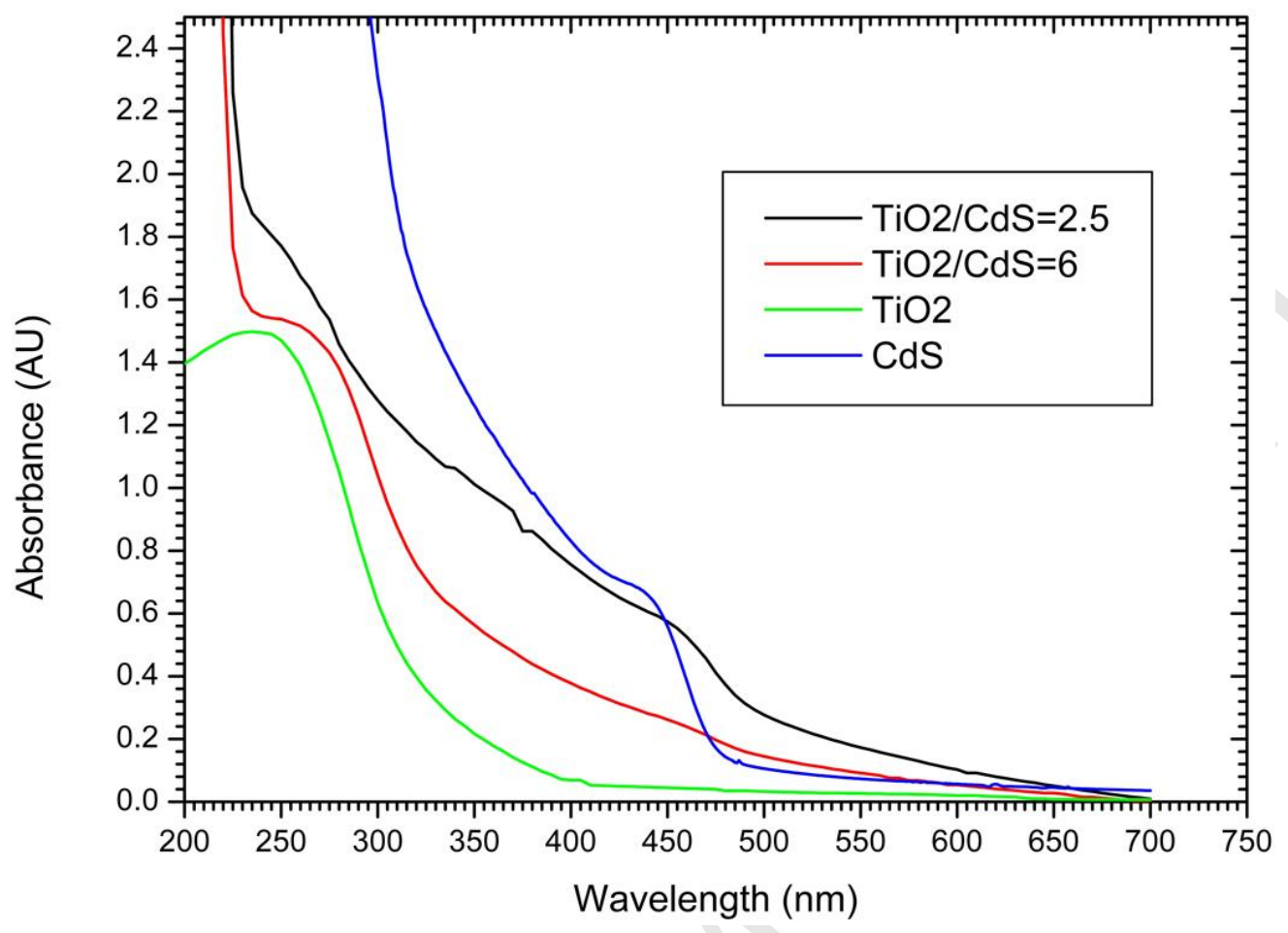

Figure 8. 


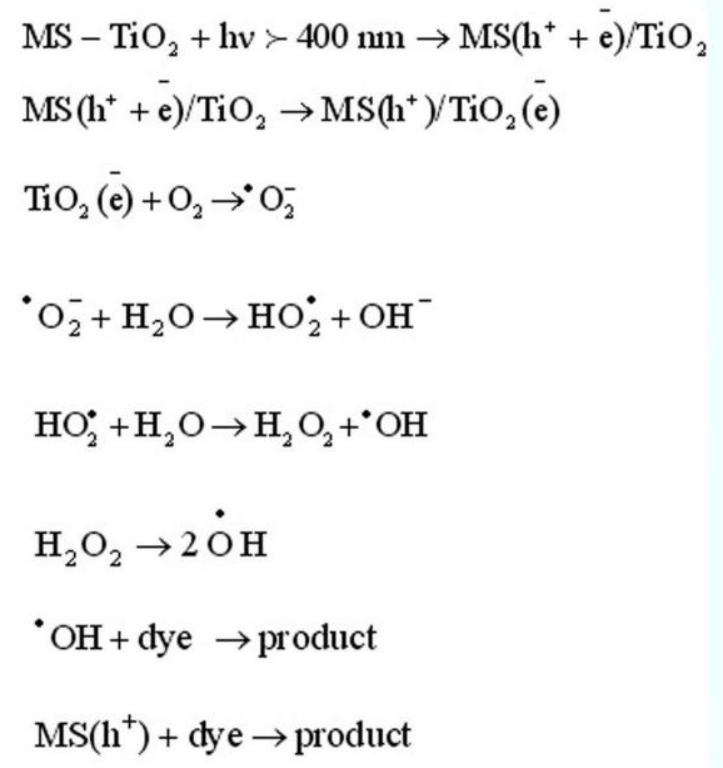

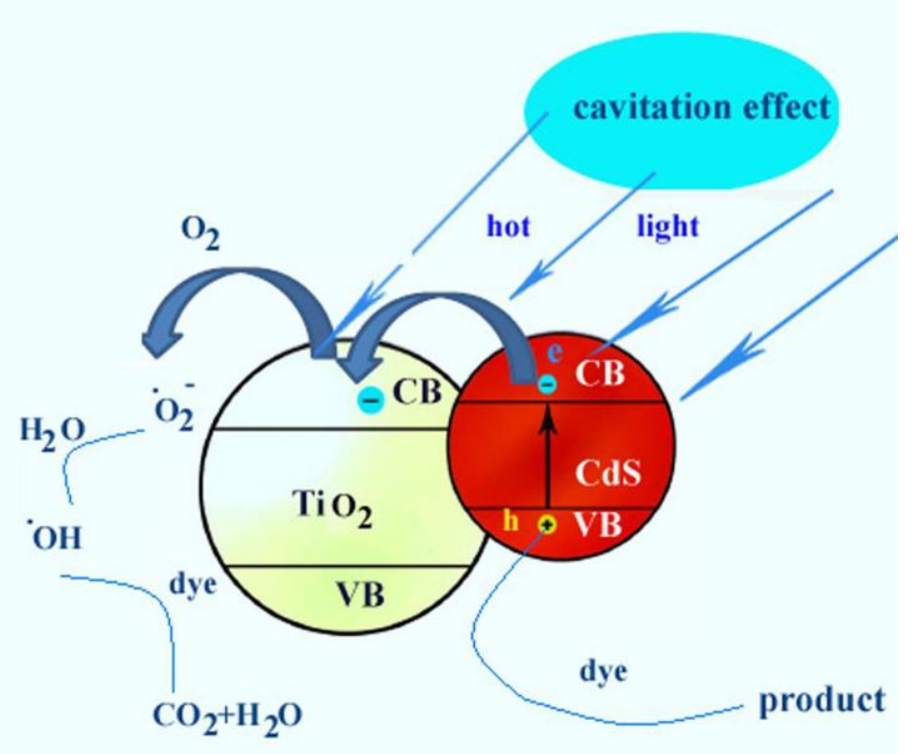

Figure 9. 


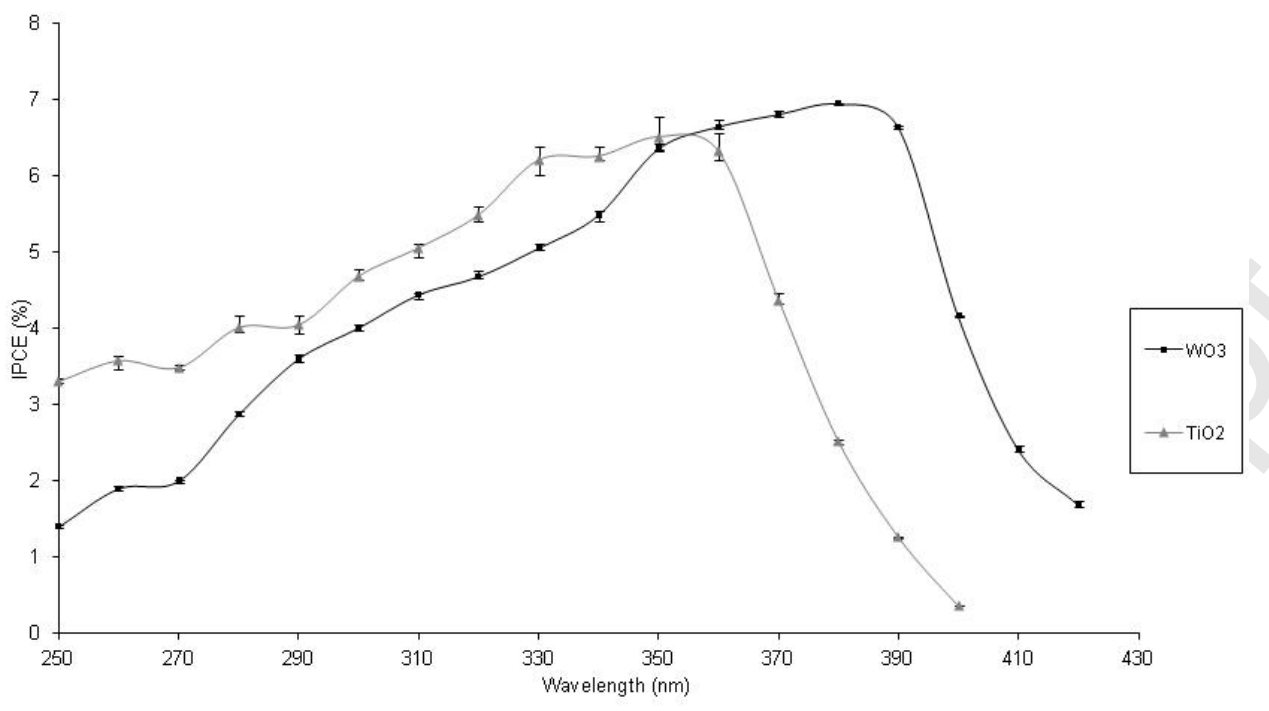

Figure 10. 

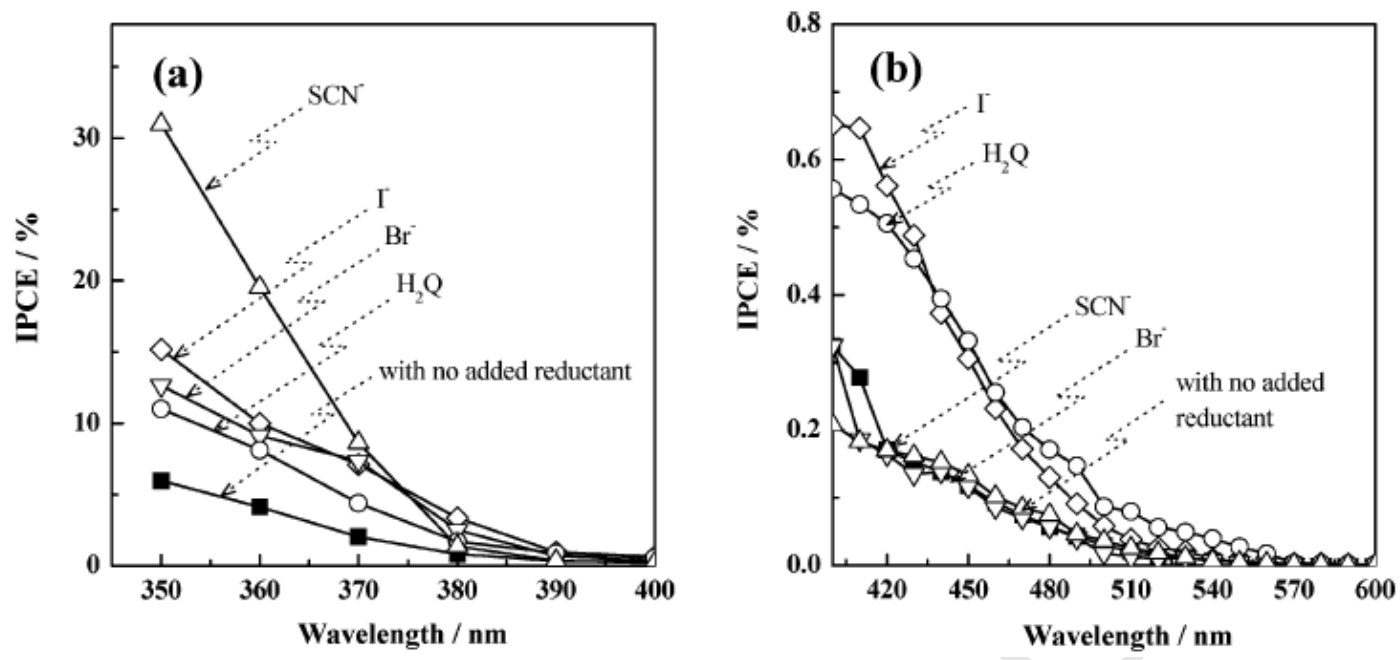

Figure 11. 


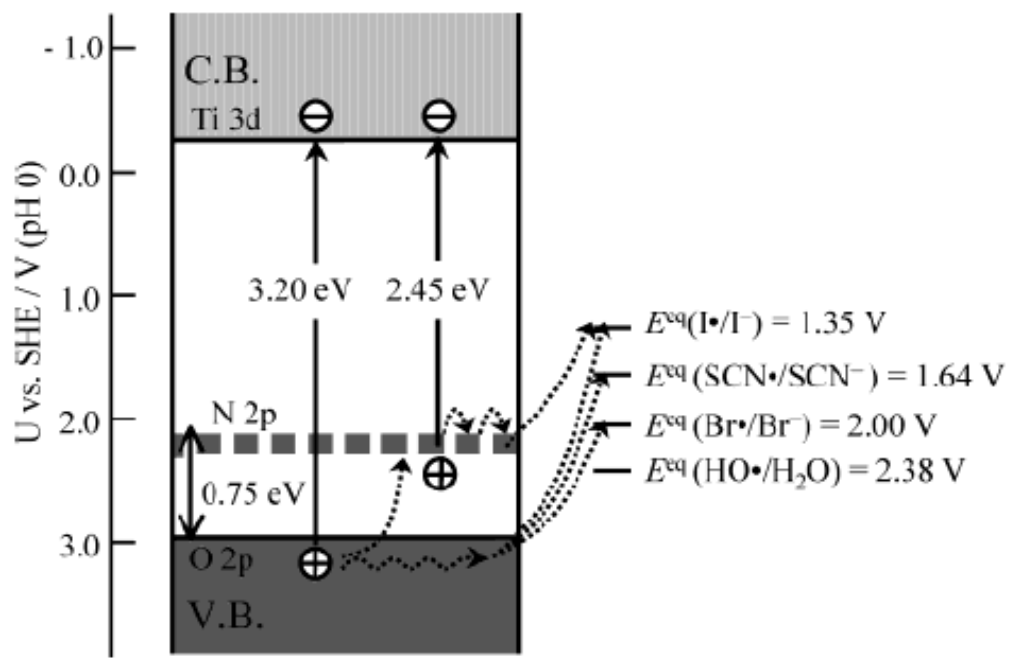

Figure 12. 

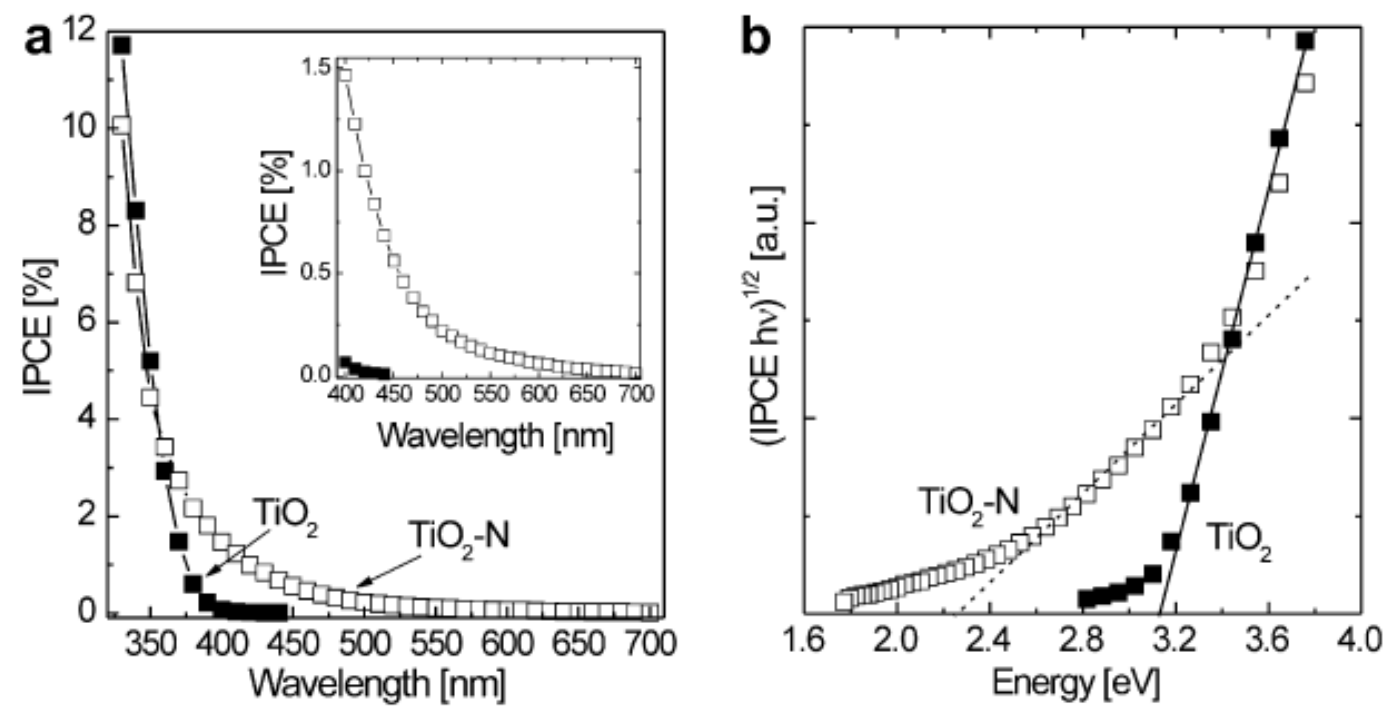

Figure 13. 

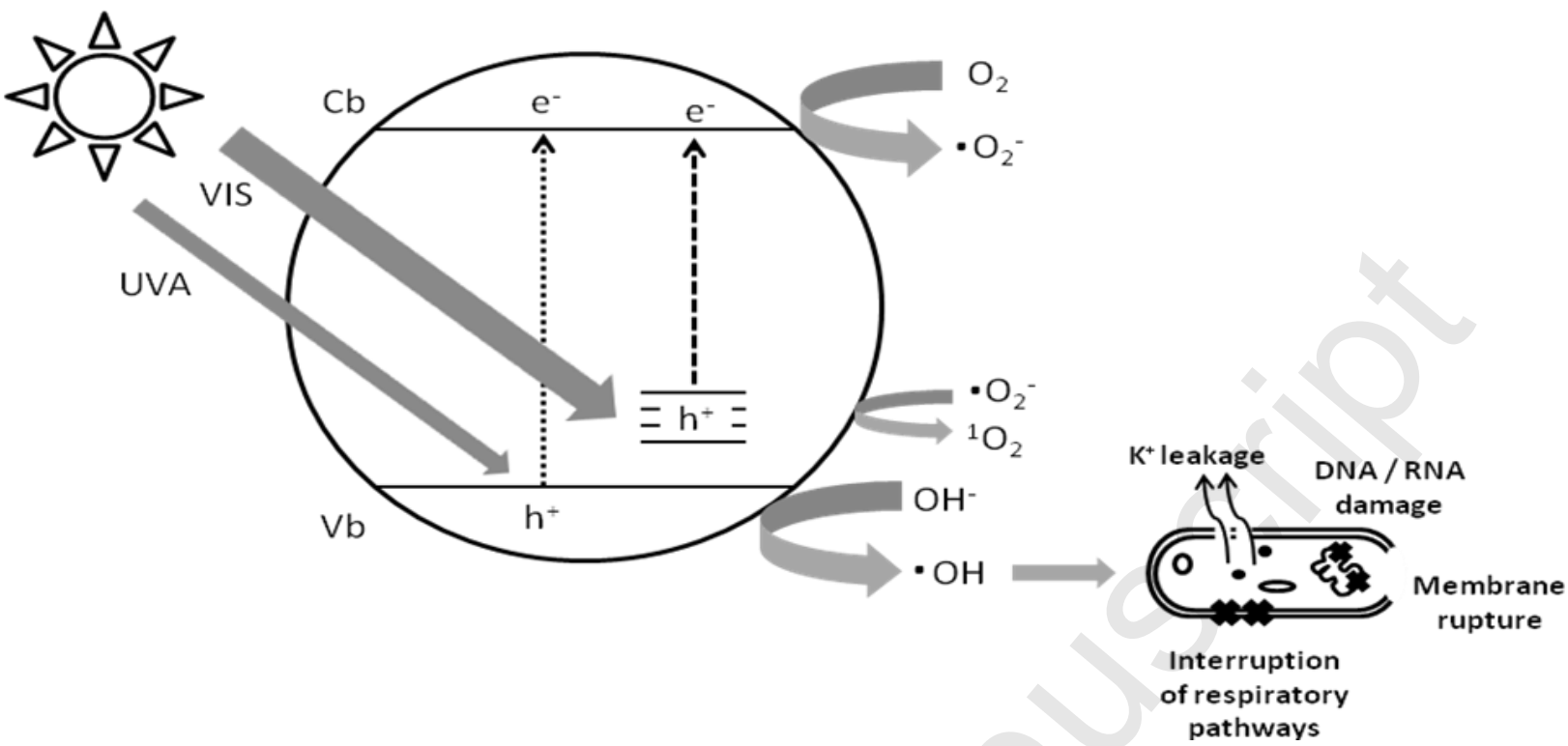

Figure 14. 


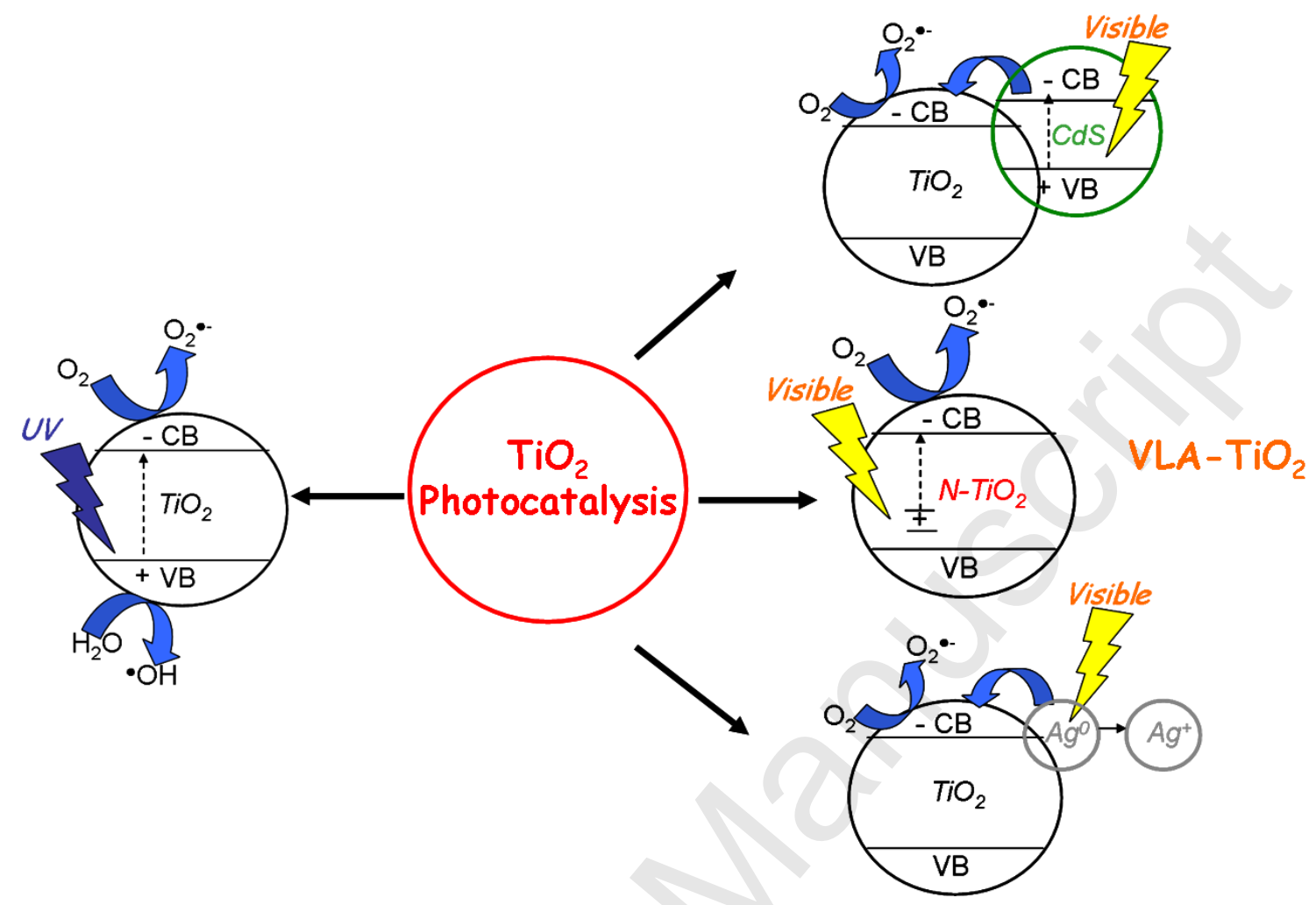




\section{Research Highlights}

$>\mathrm{VLA}^{-\mathrm{TiO}_{2}}$ include non metal, metal doping, dye sensitized and coupling semiconductors $>$ Physicochemical/photoelectrochemical methods to deduce $\mathrm{VLA}-\mathrm{TiO}_{2}$

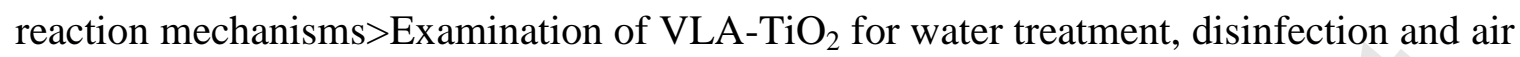
purification. 